\title{
HIV/AIDS Knowledge and behaviour: Have information campaigns reduced HIV infection? The case of Kenya
}

\author{
Markus Frölich $^{\mathrm{a}}$ and Rosalia Vazquez-Alvarez ${ }^{\mathrm{b}}$ \\ University of St.Gallen, Swiss Institute for Empirical Economic Research (SEW) \\ Swiss Institute for International Economics \\ and Applied Economic Research \\ University of St.Gallen
}

This version: February $2008^{*}$

\begin{abstract}
AIDS continues to have a devastating effect on developing countries, particularly in Sub-Saharan Africa. The lack of a proven effective vaccine to stop HIV transmission has lead to much of public policy putting an emphasis on information campaigns in order to reduce HIV-prevalence. In this paper we examine the impact of HIV/AIDSknowledge from two sides. First, we examine to what extent the campaigns have been successful at inducing the expected behavioural change with regards to HIV-related attitudes. Second, we examine the impact of HIV/AIDS knowledge on HIV status. The basic policy issue can be expressed as follows: even if individuals have acquired sufficient and necessary information on the basic facts about AIDS, factors such as innate risk attitudes or cultural background could undermine the effects of the campaigns. Using the Kenya Demographic and Health Survey (2003) we elicit empirical evidence on the relation between declared HIV/AIDS-knowledge, behavioural attitudes related to HIV/AIDS situations and the relation between knowledge and observed HIV-status. Overall, our empirical findings suggest that information campaigns have been effective at equipping the adult population in Kenya with the required knowledge to avoid becoming HIV-positive. However, when HIV-status is measured objectively we find that the relation between correctly declared attitudes and actual behaviour is only statistically significant for females that have arrived into sexuality late enough to benefit from such campaigns: it is for these females that the impact of the information campaigns has been to statistically reduce the probability of becoming HIV-positive, as intended. In the case of males we find that there is no statistical relation between either knowledge or timing of the information campaigns and a positive HIV-status. Nevertheless, another important finding refers to the selection bias induced by males who are sampled randomly but decline to take the HIV-test. The consequences of this bias are twofold; first, the estimated policy parameters for males should be interpreted with caution, but more importantly, estimating the population level HIV-prevalence for Kenyan males based on the DHS implies underestimating the true and unknown prevalence rate. Our analysis controls for individual characteristics, selection bias and endogeneity effects thus allowing us to make inferences for the full population and with regards to policy implementation.
\end{abstract}

Keywords: HIV/AIDS, education, information campaigns, Africa.

JEL - Classification: I10, O15, C21, C14

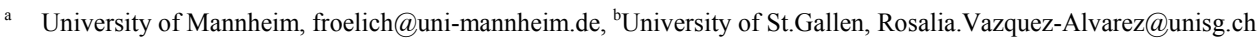

* This paper is part of the project Community Based Development Programme (CBDP). Both authors are affiliated to the Swiss Institute for Empirical Economic Research (SEW), Department of Economics, University of St.Gallen, Varnbüelstrasse 14, 9000 St.Gallen, Switzerland. The first author is affiliated to the Institute for the Study of Labour (IZA), Bonn, and the Institute of Labour Market Policy Evaluation (IFAU), Uppsala. The second author is affiliated to the Institute for the Study of Social Change (ISSC), Dublin. We are grateful to Ravi Kanbur, an anonymous referee and to participants at the May 2007 Conference 'Bottom Up interventions' (Nairobi, Kenya) for very valuable comments. We acknowledge and are grateful to the African Economic Research Consortium (AERC) and the Richard Büchner Stiftung for financial support. All remaining errors are our own. 


\section{Introduction}

According to the latest published figures, at the end of 2007 there were approximately 35 million people worldwide living with the Human Immunodeficiency Virus (HIV), the agent that causes Acquired Immunodeficiency Syndrome (AIDS). Although the global HIV incidence rate peaked in the late 1990s, many countries in Africa keep on experiencing significant increases in both incidence and prevalence rates. For example, antenatal clinic surveillance and national surveys show that since 2000 there has been a decline in HIV prevalence in Kenya, Uganda and Zimbabwe while other countries (Mozambique, South Africa and Swaziland) have remained at the steep section of the prevalence curve. However, even when prevalence rates level off they tend to remain at rather high levels, e.g. at about 6 to $7 \%$ in Kenya, $8.1 \%$ in Tanzania or $6.7 \%$ in Uganda (UNAIDS, 2006 Epidemiological update). A levelling of the prevalence implies that conditional on mortality rates the prevalence remains high as result of new HIV infections.

Without an effective vaccine to stop HIV transmission and with so far very expensive medical treatment ${ }^{1}$ information campaigns are considered to be the most cost effective public response to reduce the number of new infections as a percentage of exiting ones, i.e., the incidence rate. In theory, even when the HIV prevalence is strikingly high (e.g., at about $25 \%$ to $30 \%$ as it is currently the case in Botswana or South Africa) inducing prudent behaviour may lead to complete eradication of the epidemic (Levy, 2001). This is in fact the aim of information campaigns that deliver knowledge and awareness about HIV/AIDS with the hope that such knowledge induces individuals towards preventive behaviour. In practice, however, information and knowledge alone may be insufficient to eradicate new infections if individuals are not infinitely risk averse. The reasons are clear: the routes most commonly associated with HIV-infection lead via sexual behaviour or intravenous drug use (IDU). Those engaged in IDU are rational addicts that will maximise utility subject to tomorrow's expected returns from consuming the drug, thus today's risk associated with the use of needles might not necessarily play a large role relative to the gains of

\footnotetext{
${ }^{1}$ The triple medical treatment known as HAART (Highly Active Anti-Retroviral Treatment) has been shown to effectively reduce the viral load to almost undetectable levels thus providing protection from infection as shown in relatively small pilot studies with zero-discordant couples (Montaner et al., 2006). However, effectiveness of such
} 
instantaneously consuming the drug (see, for example, Becker, Grossman and Murphy, 1994, for the effect of instantaneous satisfaction of goods that induce negative health outcomes). Likewise, choosing between risky and non-risky sexual behaviour might imply an instantaneous investment decision that takes into account the 'immediate' satisfaction and not the long-term effects of such decision (Levy, 2001). Hence, due to behavioural reasons, even if campaigns achieve perfect and universal knowledge about HIV/AIDS both incidence and prevalence rates could remain positive.

In this paper we use the 2003 Demographic and Health Survey from Kenya (DHS-Kenya, 2003) to assess the causal relation from HIV knowledge to HIV status and the causal relation from knowledge to declared HIV-risk related behaviour. The advantage in using the DHS-Kenya 2003 data is that it is representative countrywide while containing extensive information on HIV-related knowledge and HIVrelated risk attitudes, for example, declared number of partners or declared use of contraceptives but to mention a few. At the same time the data contains the results of HIV-testing from a random sample of individuals who have initially answered the core DHS questionnaire. This provides the basis for us to estimate the causal relation between individuals' HIV-status and their HIV/AIDS related knowledge. Alongside data centred on HIV-related issues, the DHS is very informative on social, economic and demographic outcomes that provide a rich source of information to control for confounding effects when estimating causal paths between HIV knowledge, HIV-risk related attitudes and HIV-status. However, the cross-sectional nature of the data implies that causal paths between knowledge and HIV-status may not be observationally clear such that endogeneity problems may lead us to estimate spurious effects. For example, declared HIV-knowledge may be the result of the individual's HIV-positive status, i.e., knowledge about the virus and its consequence may be acquired after the individual becomes HIV-positive, either as a result of visits to the doctor or as result of innate interest that arises motivated by the interest to increase survival. Hence, reversed causality may be present. Likewise, unobserved variables to the researcher such as motivation or innate ability may be causal to both the individual's declared knowledge on HIV-related issues and the individual's HIV-status. This unobserved third variables problem may also create potential

treatment requires constant monitoring for the effect to be long lasting (e.g., diversification of the drug in the event that the virus becomes resistant) while effectiveness of any triple drug treatment requires persistent adherences. 
endogeneity problems. We solve these and other estimation problems via instrumental variables and by experimenting with sub-samples of individuals who differ with regards to their declared history of HIVtesting. ${ }^{2}$ When instrumental variables are used the set includes 'access to information channels', i.e., variables that informs us about the individual's exposure to radio listening, access to newspapers and/or access to television. These instruments are carefully measured so that - conditional on the available information - they are as independent as possible from the idiosyncratic characteristics of the individual.

Besides the potential endogeneity effects previously mentioned, our estimates may also be subject to selection bias. The reason for this is that not all in the randomly selected sample for blood testing accepted to give blood, not even under assurance of anonymity of results and hygiene in the procedure. It cannot be assumed that refusal to participate in the randomised testing is itself random. Thus, our estimates on the effect of declared HIV/AIDS- knowledge on HIV-status use a three step estimation procedure that not only reduces the potential endogeneity effects but also aims at controlling for possible selection bias that would result in the presence of a selected HIV-testing sample. In the process, all our estimates are based on specifications that control for many individual and household characteristics that imply comparing individuals in a common support with regards to social and economic characteristics.

Our estimates provide empirical evidence that support the positive effect that information campaigns have had in terms of shifting the behaviour and attitude in the population; i.e., for both males and females fact-based knowledge about HIV/AIDS is statistically causal at inducing the population to declare intended behaviour and attitudes that are required to reduce the spread of HIV - e.g., agreeing that it is important to reduce the number of partners, to use condoms regularly or that it is important to target school age children with regards to sexual education. However, when using objective HIV-status measures it seems that the campaigns have been effective at the adverse effects of HIV/AIDS only for females and only if such information campaigns have arrived early enough to induce a behavioural change before the

\footnotetext{
${ }^{2}$ We notice at this point that although the DHS tests a random sample of individuals these subjects are not given the results of the test. However, previous to the survey taking place individuals may have had a HIV-test on their own accord. We use declared information on the individual's testing history to compare estimated coefficients from different sub-samples (including the complete sample) according to their possible knowledge on HIV status as a way to provide us with understanding on the possibility of reverse causality.
} 
female became part of the population at risk. On the other hand, information campaigns and timing of these campaigns cannot explain the HIV-status for the males in the population, although it may be that those who decide to take part in the test self-select themselves and, consequently and only in the case of males, the policy parameters of interests are potentially subject to sample selection bias. Our estimates take into account not only selection bias but also possible endogeneity problems. Thus, given that our sample is representative country-wide our estimates may be used to make inference from the sample to the population.

The paper is organized as follows. Section 2 reviews the background of the HIV/AIDS pandemic and the state of potential interventions that aim at eradicating the rate of infection. Section 3 explains the DHS-Kenya 2003 this being the data used in the empirical section. Section 4 explains the identification issues that mark the econometric methods employed in the paper and provides the first set of empirical results showing the effect of HIV/AIDS knowledge on HIV/AIDS related attitudes. This first set of results explores the extent to which acquired knowledge affects potential risk-related behaviour. Section 5 further reviews required identification strategies in the presence of non-random HIV-testing response and provides the empirical evidence on the conditional causal effect of HIV-knowledge on HIV-status. Section 6 concludes. A set of appendices collects any further results and background information.

\section{Background to HIVIAIDS: The case of Sub-Saharan Africa}

Recent estimates from UNAIDS, the United Nations Agency for the control and prevention of HIV/AIDS, show that countries in Sub-Saharan Africa (SSA) still bare the highest burden of the global HIV/AIDS epidemic: $66 \%$ of all HIV cases worldwide (23 out of 35 million HIV cases) live in SSA, while 2.4 out of all 4.3 million estimated new HIV cases worldwide in 2006 (i.e., $65 \%$ of all new infections) also occurred in SSA countries. In fact, the overall estimated HIV-prevalence in SSA approximates 6\%, compared to a $1 \%$ prevalence rate worldwide. Likewise, while the incidence rate in SSA is estimated at about $10 \%$, the worldwide incidence rate is significantly lower at less than $0.5 \%$.

The short and medium term consequences of HIV-infection can be defined in terms of morbidity with the resulting loss of healthy time and consequent loss in stocks of health and productive capacity. For 
example, Lopez et al. (2006) use the measure Disability Adjusted Life Expectancy (DALY) to estimate that $17 \%$ of healthy years lost as result of communicable diseases ${ }^{3}$ were a direct consequence of HIV/AIDS and whereas HIV/AIDS is the fourth leading cause of the Burden of Disease globally it becomes the first leading cause in the case of SSA countries (see Lopez et al., 2006, Table 1.1). This figures show not just the psychological but also the growth-related consequences of HIV/AIDS for these economies: the direct application of Grossman's concept of lost healthy time and lost productive capacity implies a severe loss of consumption and productivity and further impoverishment for those who suffer the morbidity effects of the illness. Besides the effects of morbidity at the individual level, the effects of mortality in terms of reduced aggregate growth are also significant for SSA countries where deaths due to AIDS during 2006 accounted for $72 \%$ of all AIDS related deaths worldwide.

However, the effect of HIV/AIDS is by no means uniform across all African countries. Although (slow) changes in risk-related behaviour and an increasing use of retroviral treatment has reduced both the rate of infection and mortality rates for Southern African countries (WHO, 2006) the difference in HIVprevalence between Southern and Eastern African countries remains striking. Countries such as Ethiopia (with an estimated prevalence of $2 \%$ ), Eritrea (3\%), Uganda $(6.7 \%)$, Kenya $(7 \%)$ or Tanzania $(8.1 \%)$ remain high HIV-prevalence countries when compared to global averages, but the average HIV-prevalence in these countries (6-7\%) contrasts drastically with the HIV-prevalence in countries such as Swaziland (33\%), Zimbabwe (30\%), South Africa (30\%), Botswana (24\%), Namibia (24\%) or Lesotho (22\%) with these five last countries being the ones that lead the HIV-prevalence rate worldwide. ${ }^{4}$

The relatively low HIV-prevalence in East Africa is the result of a relatively prompt response to the epidemic on behalf of both internal (i.e., governmental) and external interventions (e.g., on behalf of NGO and UN-related agencies) mostly in the form of intensive information campaigns. An example of this is found when reviewing the history of the HIV/AIDS epidemic in Uganda. In this country the first cases of

\footnotetext{
${ }^{3}$ The groups include communicable, antenatal and nutritional diseases, that is, tuberculosis, HIV/AIDS, diarrhoea, measles, malaria, communicable respiratory infections, prenatal conditions and malnutrition effects. The Burden of Disease implies a measure of current health status relative to some ideal health status where only the ageing process is responsible for life expectancy and longevity.

${ }^{4}$ Unless otherwise mentioned all aggregated figures in this paper are drawn from the 2006 AIDS Epidemic Update (UNAIDS, December 2006) and/or the Word Health Organization Fact Sheets, 2005-2006.
} 
HIV/AIDS were recorded in 1982. By 1986, and when the country was already experiencing a HIVprevalence rate of approximately $20 \%$, the government health authorities together with non-governmental agencies put forward an intensive information campaign applicable to both rural and urban areas. These campaigns disseminated information by means of large and small community organized meetings, one-toone discussions from health workers to individuals, the use of public and private telecommunication services, distribution of information leaflets and the use of local drama and video shows (see deWalque, 2002, and Kamali et al., 2003). Similar campaigns have been applied in neighbouring countries, e.g., Kenya and Tanzania. In the case of Kenya, the first diagnosed cases were in 1984. Figure 1 shows the HIVprevalence for Kenya with the epidemic peaking at about 14\% between December 1999 and January 2000.

Figure 1: HIV-Prevalence rate in Kenya (1984 to 2005)

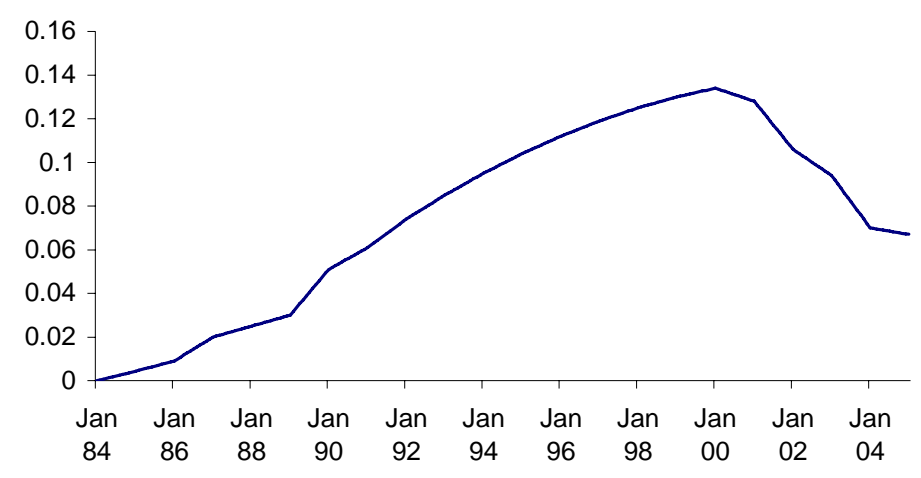

Source: Yearly figures from Kenya Ministry of Health, 2005. Adult population (age 15 to 49). Monthly figures interpolated.

Relative to the Ugandan authorities, the Kenyan authorities delayed their response to the HIV epidemic and it was not until November 1999 (i.e., 15 years after the first recorded cases) when the first intensive information campaigns were initiated countrywide. ${ }^{5}$ Since then, as it is clear from Figure 1, HIVprevalence has declined drastically: some of the decline is due to changing behaviour - e.g., increased age of sexual debut, increased use of condoms and a fewer individuals with multiple partners - but also as result of AIDS mortality and the saturation of infections among people most at risk (UNAIDS, 2006).

\footnotetext{
${ }^{5}$ The first time that Kenyan public health agencies reacted to the HIV problem in the country was as a result of the observed mortality rate due to AIDS in 1997 when AIDS accounted for approximately 75,000 deaths per year by the end of 1998 (Orege, 2005). The first reaction was to enact a set of policy guidelines (Session Paper number 4 of 1997 on AIDS in Kenya, Kenyan National AIDS control council) but it was not until the $25^{\text {th }}$ of November, 1999 , when the first intensive information campaigns were started with President Moi appearing on TV, radio and other media channels holding hands with ordinary citizens and declaring HIV/AIDS to be a national disaster (Sihanya, 2005).
} 
To some extent the effect that AIDS related mortality has had in reducing overall HIV-prevalence has been similar for all Eastern African countries: nowadays mortality as consequence of developing from HIV to AIDS is still at the increasing slope for most SSA countries (UNAIDS, 2006) including Eastern African countries. In the case of Kenya the number of deaths as consequence of AIDS has dropped from around 150,000 in the year 2003 to around 85,000 in 2006 , a drop that can be explained due to the combined effect of 'survival bias' and an increase in the number of HIV-positive individuals put into Anti Retroviral treatment (ART treatment). Thus, despite the fact that only some $20 \%$ of those in need of ART treatment in Kenya receive it, it does imply a substantial increase in the number of treated individuals since AIDS related mortality rates peaked in the late 1990 s - early 2000 s. $^{6}$

The consequence of mortality of old AIDS cases, an increased survival of HIV-positive individuals together with a saturation of infection among people more at risk has lead to HIV-prevalence in Kenya levelling out at around 6-7\% of the adult population (Cheluget et al., 2006). But a levelling of HIVprevalence implies new infections arrive at the same rate as mortality rates due to HIV/AIDS. That is, despite the observed behavioural change in the adult population a significant proportion of individuals become newly infected every day thus precluding the desired HIV-prevalence decline. The problem is not identical among sub-groups in the population and neither is the response behaviour. For example, based on surveillance data (UNAIDS2006) prevalence rates in Kenya differ by gender (the HIV-prevalence in males is estimated at $5 \%$ and $8 \%$ for females), between rural and urban areas (10\% versus $6 \%$, respectively) and between sub-groups according to infection route (e.g., the prevalence among intravenous drug users has risen significantly in the past decade with HIV-prevalence rates of 50\% and 53\% among IDU in Mombassa and Nairobi, respectively). Likewise, poverty can also determine the probability of becoming HIV-positive: Zulu et al., (2002) looked at the difference among women living in slum versus non-slum areas in Nairobi to find that educated women in 'non-slums' are statistically significant factors that reduce exposure to HIVrisk related situations (e.g., early start into sexual live). Zulu et al. (2002) also shows that there is a significant gap in terms of HIV-related knowledge comparing Nairobian women living in slums to

\footnotetext{
${ }^{6}$ See the National Aids Control Council webpage for currently updated information on those receiving treatment in Kenya, www.nacc.or.ke
} 
Nairobian women living in non-slum areas, a finding that was maintained after controlling for the effect of migration from rural to urban areas since migrants from rural towns with significantly different exposure to knowledge are more likely to locate themselves in the slums of Nairobi.

Information campaigns aim at targeting the population at large irrespective of sub-population differentials in terms of HIV-risk related factors. So far these campaigns are seen as the most cost effective tools in the aim to eradicate current HIV/AIDS trends. Thus, the use of Voluntary Counselling and Testing centres (VCT-centres), radio-televised information campaigns and the impulsion of community based organizations and meetings remain the cornerstone in the aim to modify individual's behaviour in situations where contracting the virus becomes more likely, for example, modify individual's perceptions on the use of condoms, number of partners, age of sexual debut and the consequences of intravenous drug use. Information campaigns also aim at breaking down myths that may increase the risk of discrimination while creating misunderstanding with regards to HIV/AIDS transmission (e.g., see Yamba, 1997, for some initial effects of AIDS on individual's built up myths and believes in Africa). But information campaigns are costly and divert scarce resources from other policy actions. For example, the official 2006 UNAIDS report suggests that together, lowest income African countries have allocated approximately US $\$ 2.5$ billion for the purpose to reduce the effect of HIV/AIDS on their populations. ${ }^{7}$ It is therefore natural to question the effectiveness of such expenditure since most of it is associated with programs that aim at modifying HIVrisk related behaviour. In the event that information campaigns work, these would eventually lead to a decline in HIV-prevalence as result of an effective reduction in new cases (incidence) in the population, and not just as the result of mortality among those who develop AIDS. As it is nowadays, the HIV-prevalence observed in Kenya and surrounding Eastern African countries remains high enough to deem these unacceptable. Moreover, UNAIDS has recently reported a potential erosion of thus far stabilized/declining rates in neighbouring countries such as Uganda that cannot be explained exclusively as a consequence of reduced mortality rates from increased use of ART treatment. This may have resulted from a general relaxation in terms of behavioural attitudes (possibly driven by the population observing better survival 
rates) that would imply a negative externality emanating from the information campaigns themselves (e.g., based on surveillance in rural Uganda, Shafer et al. (2006) report an increase in the number of individuals with multiple casual partners between 2000 and 2004 for populations ages greater than 49, that is, for those populations that were of prime age when the first information campaigns were imposed in Uganda).

Thus, information campaigns have to be innovative as well as employ resources such that 'the information' targets those who have but also those who have not natural access to the required stock of knowledge. Only then will a policy based on information become an effective policy tool. For example, estimates from Kenya's 2003 Demographic and Health Survey (DHS) show that $30 \%$ of those classified in the lowest wealth deciles have not heard about sexually transmitted infections (STI) while $68 \%$ in the same sub-group have poor or no knowledge in terms of avoiding HIV/AIDS. In contrast only $2 \%$ from the top wealth deciles have not heard about STI while at most $13 \%$ of these have poor or no knowledge in terms of avoiding HIV/AIDS. These estimates imply a significant difference in terms of health and knowledge with poor HIV/AIDS knowledge clearly correlated to poverty. A comparative analysis of HIV/AIDS-knowledge using the variable 'education' reveals a similar picture: individuals with no schooling or less than completed primary education are less likely to be associated with the stock of knowledge required to avoid infection, possibly as consequence of no access to schools or primary health facilities. ${ }^{8}$ These estimates based on the Kenya-DHS from 2003 provide further backing for the findings in Zulu et al., (2002). Furthermore, these estimates suggest that despite extensive and expensive implementation of information campaigns in Kenya, and despite the observed reduced HIV-prevalence (by $1 / 2$ of the HIV-prevalence of the late 1990s) the prevalence itself has levelled out at what may be deem as a very high rate within a social framework where HIV-prevalence remains more detrimental for those living in disadvantaged social-economic groups. Clearly, most empirical evidences would suggest that the campaigns are not equally distributed among all socio-demographic groups in the population.

\footnotetext{
${ }^{7}$ According to UNAIDS 2006 reports, spending in low income African countries has aimed at both increasing medical treatment so to cover at least $50 \%$ of those infected with HIV in the population, but mostly the spending has been on promoting knowledge transfers that hopes to modify HIV-risk related behaviour among their citizens.

${ }^{8}$ For example, a detail analysis of newly mothers from the KDHS-2003 reveals that those mothers with lower education are $80 \%$ less likely to depend on antenatal care or the care of a doctor before delivery.
} 
But correct knowledge of HIV/AIDS is only part of the solution. Even in the presence of correctly acquired information by means of campaigns, individual's innate risk behaviour may be the driving force behind the prevailing HIV-rate. Furthermore, cultural and religious attitudes are also factors that may undermine the effect of disseminating the required information by means of countrywide campaigns.

The key requirement in order to evaluate the effect of information campaigns is the availability of sound quantitative data both on the distribution of HIV-related knowledge and the behavioural attitudes of individuals in the population. We emphasize the word 'distribution' because for any quantitative analysis to have relevance in terms of policy impact there is a need to study the effects of information campaigns at the microeconomic level where estimation of heterogeneous effects are part of the analysis. For example, allowing for aggregates may lead us to conclude that $50 \%$ of those between ages 15 to 18 in Kenya have poor knowledge in terms of HIV/AIDS prevention (DHS, Kenya 2003). But these numbers hide the social economic composition of those who display such poor knowledge. Likewise, macroeconomic aggregates do not allow the targeting of specific sub-groups that may differ from the average in the population with respect to holding the required level of knowledge required to induce prevention when faced with risky situations.

Analysis at the microeconomic level that allows for heterogeneity in policy evaluation further requires the use of representative data of the population. It is often the case that the data used to analyze the spread of HIV in low income countries (e.g., African countries) comes from antenatal clinics where women are the target group. Other data sources are experimental (or quasi-experimental) based on surveillance data that targets a few villages or communities and are not necessarily representative of the population (e.g., deWalque, 2002 and Kamali, 2003). Inference from selected groups to the full population requires caution.

Alternative data sets are available and can potentially help to solve the problem and provide unbiased population estimates from the sample analogue. These are national level surveys that cover a random sample of villages thus surveying individuals, households and communities on issues directly relevant to socioeconomic outcomes (e.g., employment, income or consumption) as well as extensive information on HIV knowledge, HIV related risk behaviour and clinical data on HIV testing. Examples are the Demographic Health Surveys (DHS) and companion data sets on HIV-testing (AIS data). The DHS and 
AIS data do not provide panel structure for the dynamic analysis of policy implementation but nevertheless permit cross-sectional analysis allowing for effects heterogeneity.

The main topic of our empirical analysis is to understand both the causal relation between HIVstatus and the stock of HIV/AIDS related knowledge and the relation between HIV/AIDS knowledge and HIV/AIDS related (declared) attitudes. Clearly, in the absence of time varying data it is difficult to determine with certainty such causal paths (at the microeconomic level). However, the use of adequate econometric tools and the use of the Kenya DHS 2003 can be sufficiently adequate to elicit policy parameters while controlling for possible selection bias and potential endogeneity problems.

\section{The 2003 Kenyan Demographic and Heath Survey}

The data used in our empirical analysis draws from the 2003 Demographic and Health Survey for Kenya (DHS-2003). The DHS survey aims at collecting, analysing and disseminating representative data on social and demographic aspects from developing countries. ${ }^{9}$ All DHS are cross-sections representative of some population at a given point in time. Thus, although previous DHS have been conducted in Kenya (1989, 1993 and 1998), they are independent cross-sections without panel data structure.

The KDHS-2003 was collected between January and April of 2003 in 400 randomly chosen geographical clusters. Originally, 8,561 households are selected to represent the full Kenyan population. The survey design determines the household representative that will answer questions at household level. Thereafter, a random procedure selects males and females from each household. In total 8,717 females and 4,377 males are selected to represent social and economic conditions of the respective genders in the Kenyan population with ages between 15 and $50 .{ }^{10}$ The initial selection is such that only 8,195 females and 3,578 males accept full participation to answer the DHS questionnaire, thus there is an initial unit nonresponse of $10 \%$. The core questionnaire is similar between genders except that females answer questions specifically relating to reproduction (pregnancy, postnatal care and breastfeeding) and questions relating to their children when these are of age 5 or below. A random selection of women is also asked questions on

\footnotetext{
${ }^{9}$ See www.measuredhs.org and www.usaid.org for further details on the DHS initiative.

${ }^{10}$ The target age represents adults in the population more at risk in terms of HIV-status.
} 
domestic violence while a random selection of males, females and children is asked to provide anthropometric data.

Relative to previous Kenyan DHS, the DHS-2003 is special because a random sample of 8,800 from the original 13,094 selected units (i.e., from the 4,377 males and 8,717 females) were asked to participate in an anonymous randomised HIV-test. Individuals are guaranteed full anonymity and hygienic conditions but it is also made clear to them that providing the blood-sample is voluntary. In addition, they will not be given the test result. Not everyone donates blood with a significant percentage refusing to do so (or because a family member rejects consent on behalf of the selected person). This result implies unitnonresponse to be accounted for in the event that HIV-status becomes the outcome of interest (see Section 5). Table 1 shows the distribution of the sample with respect to response behaviour distinguishing between males and females.

Table 1: Sample sizes according to response behaviour and gender sub-group

\begin{tabular}{|c|c|c|c|}
\hline & Full Sample & Males & Females \\
\hline Size: original eligible sample selected for DHS questionnaire & 12,952 & 4,377 & 8,573 \\
\hline Respondents to the DHS & 11,773 & 3,578 & 8,187 \\
\hline Size: original Sample selection for HIV-testing & 8,800 & 4,377 & 4,417 \\
\hline Non-respondents to CORE DHS before been asked for blood & 1,185 & 799 & 380 \\
\hline Respond to CORE DHS \& HIV-testing & 6,186 & 2,917 & 3,269 \\
\hline Respond to CORE DHS but refuse HIV-testing & 1,429 & 661 & 768 \\
\hline $\begin{array}{l}\text { The survey designers contacted 8,561 households to repr } \\
\text { households was } 37,612 \text { (including infants, children and } \\
\text { permanent inhabitants in the household. From these a rar } \\
\text { core KDHS- } 2003 \text { questionnaires. }\end{array}$ & $\begin{array}{l}\text { full Kenyan p } \\
\text { household } \\
\text { ction of male }\end{array}$ & $\begin{array}{l}\text { of indi } \\
\text { the fu } \\
\text { tuted th }\end{array}$ & $\begin{array}{l}\text { living in these } 8,561 \\
\text { sked to declare the } \\
\text { mple answering the }\end{array}$ \\
\hline
\end{tabular}

Our interest is to understand the effect of HIV/AIDS knowledge on HIV/AIDS-related attitudes (Section 4) and HIV-status (Section 5) controlling for potential confounding effects that may affect both the 'treatment' under consideration (i.e., HIV/AIDS-knowledge) and the various outcomes of interest. What follows in this section (together with Appendix A1) provides an account of the variables representing HIV/AIDS knowledge, HIV/AIDS-related attitudes, HIV-status and confounding effects. We now discuss these sets in turn.

\subsection{Knowledge Variables and measured knowledge using Item Response Theory}

The DHS-2003 provides extensive information on individual's declared HIV/AIDS-knowledge with common questions asked to both the males and the females in the sample. Table A1 (Appendix A) shows a 
total of 29 questions (28 for females) that provide direct information on how knowledgeable individuals are with regards to the meaning of HIV/AIDS, coping mechanisms against becoming HIV-positive as well as concrete opinion on the effects of HIV/AIDS on health. The empirical distribution in Table A1 shows that although most individuals have heard about 'HIV/AIDS' (only $1 \%$ of males and $1.6 \%$ of females declare not to have heard about the condition), $9 \%$ of males and $16 \%$ of females signal incorrect knowledge when asked if HIV/AIDS can be avoided (i.e., they either declare that nothing can be done to avoid the condition or they declare not to know if something can be done to avoid the condition). Of those males who initially declare to know that HIV/AIDS can be avoidable if following a particular behaviour, $1 \%$ suggest a behaviour that would represent an incorrect approach in terms of avoiding HIV/AIDS (e.g., seek protection from the traditional healer, avoid mosquito bites or avoid kissing in general). For females the figure is similar (1.1\%). Thus, it seems that the large majority of those who declare 'knowing how to avoid HIV/AIDS' are aware at least of the basic behavioural aspects associated with becoming HIV-positive. However, despite showing basic knowledge on how to avoid HIV/AIDS, we also find that individuals hold misperceptions with regards to HIV. For example, although only 3 out of 3,259 declaring knowledge on how to avoid HIV/AIDS 'spontaneously' suggest that mosquito bites leads to a HIV-positive status, when the same sub-group is prompted with an anchor $20 \%$ answer incorrectly (i.e., do not answer 'no' when prompted with question about mosquito bites causing HIV/AIDS). ${ }^{112}$ Likewise, $11 \%$ of males answer incorrectly when asked if a 'healthy looking person can have the virus that causes AIDS' whereas for females the percentage increases to $15 \%$ (based on those who answered the question). Overall, Table A1 shows a mixed picture with regards to the distribution of effective HIV/AIDS-related knowledge in the population

11 A spontaneous answer relates to open-ended questions such as 'What do you think can be done to avoid HIV/AIDS?'. In this case individuals are asked to answer as many items as their knowledge may imply. Alternatively, an anchored question is such that the individual is prompted with specific pieces of information, for example 'Do you think that mosquito bites may cause HIV/AIDS?'

${ }^{12}$ In Sub-Saharan countries where parasitic and insect-related illnesses are common (e.g., malaria), information campaigns dealing with HIV/AIDS often include information with regards to the general health in the population, for example, the use of bed-nets to avoid other potentially harmful health conditions. If so, individuals will often be informed that mosquito bites cannot cause HIV/AIDS because the mucus from mosquito itself is what transports the effect of malaria while the virus that causes AIDS does not survive in such mucus substance. Thus, knowledge of the relation between mosquito bites and HIV/AIDS signals effective exposure to information campaigns. 
One question that arises is how to use the variables in Table A1 to produce a joint measure of 'knowledge' that allows each of the items in the table to enter with a fair weight. For example, most individuals who declare to have heard about HIV/AIDS will probably know that risky sexual behaviour increases the probability of infection, whereas knowing that a healthy looking person can also be HIVpositive may not be so common and yet can also be important information to avoid HIV-infection. Knowledge may thus have different facets: Knowledge of ways to avoid HIV and knowledge about channels that do not lead to HIV, e.g. Malaria bites, buying vegetables from an HIV positive vendor. Although the first set of knowledge appears to be more important, the second set is also helpful in showing that HIV infection is not something that is more or less unavoidable or a random event but rather under the control of the individual itself. Likewise, individuals can answer to some of the items in Table A1 by guessing, thus inserting elements of noise in causal analysis. Using each of the items in Table A1 separately as independent effects may be problematic since it would be difficult to analyse the effect to determine a unified effect of knowledge on HIV-status and/or behavioural attitudes. Another problem may be that of dimensionality: using a multiple set of binary outcome may result in empty cells and therefore identification issues. Instead one could count the number of correct answers given to the HIV/AIDS knowledge questions.

The number of correct answers, however, does not account for the fact that some questions are easier than others. To consider different degrees of difficulty and discrimination, Item Response Theory (IRT) has been developed and can be used as a statistical summary tool that transforms a finite number of dichotomous or polychromous answers into a single measure. Generally, the final output from any IRT analysis is a value for each respondent that ranks his or her ability to display proficiency with regards to some element (e.g., intelligence, cognitive performance, ability, etc) taking into account the relative difference of each of the binary components with regards to difficulty, discrimination and 'guessing' potential. The use of IRT is often found in psychology and sociology when there is a need to summarise the performance of individuals who answer a multiple number of standardized tests (e.g., cognitive tests) with closed-form questions. Our paper uses a 3-Parameter logistic IRT model to summarize all variables in Table 
A1 into a single measure of knowledge, which we denote for individual $i \in n$ as $\kappa_{i}$. More details are given in Appendix C.

Figure 2 shows a scattered plot of the HIV/AIDS knowledge among all individuals. In these figures the ordinates measure the number of correct answers and the abscissas measure the IRT value. ${ }^{13}$ These two measures of HIV/AIDS knowledge clearly display a positive correlation. This correlation is not one because of the result of the different weighting. 10 correct answers given to relatively simple question indicate less knowledge than 10 correct answers given to difficult questions. Therefore, most of our subsequent analysis uses the value of $\kappa_{i}$ resulting from IRT to capture HIV/AIDS knowledge. ${ }^{14}$

Figure 2: HIV/AIDS knowledge: Corrects answers versus Item Response Theory (IRT)
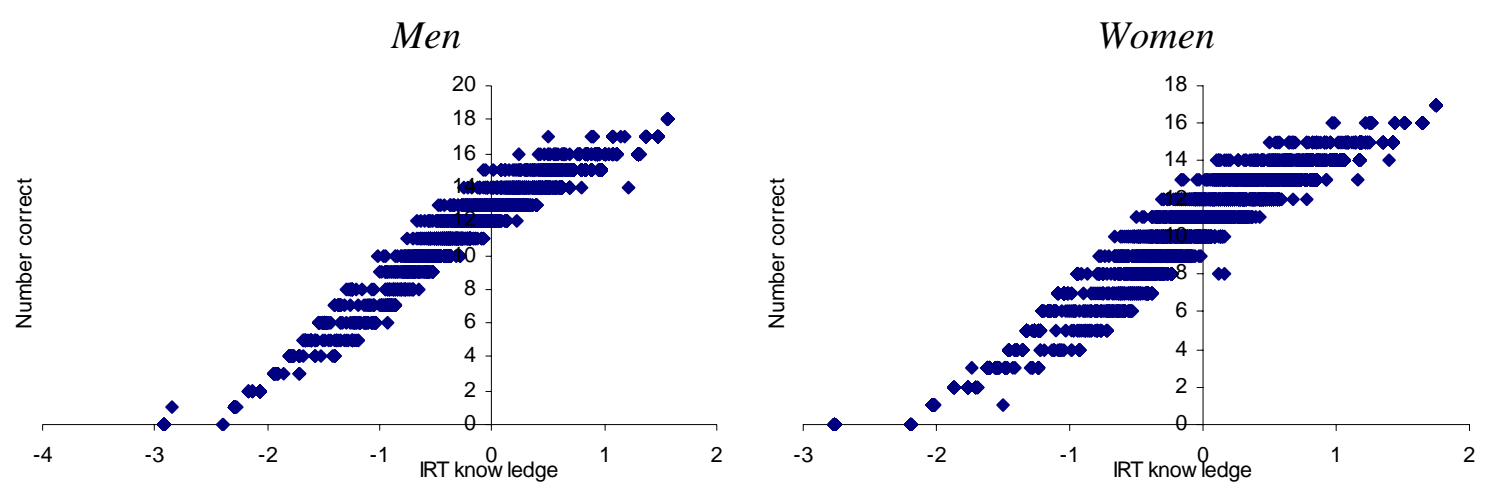

Source: DHS-2003. Relation between the number of correctly answered knowledge questions and the implied knowledge according to IRT

\subsection{HIV-attitudes and related behaviour}

The DHS-2003 is also informative about 'attitudes' that individuals hold with regards to HIV/AIDS. By attitudes we mean declared subjective stance that might be viewed as signalling intended behaviour when faced with risk-factors associated with HIV/AIDS. Thus, we consider 'attitudes' those variables that do not pose direct questions with regards to HIV/AIDS (e.g., Can people reduce the chance of getting HIV/AIDS by using condoms?) but instead they elicit information about 'intended actions' with

\footnotetext{
${ }^{13}$ We observe different values of $\kappa_{i}$ for individuals with zero correct answers. This can happen if the total number of questions being answered varied between the individuals (e.g. some of the questions might not have been applicable). Then the knowledge implied by having zero correct answers also depends on the total number of questions that could have been answered incorrectly.
} 
regards to situations where HIV/AIDS may play a role (e.g., Do you use condoms regularly during sexual intercourse?). Consequently, we think of 'attitude' variables to be those approximating individual's behaviour that would have been targeted by any of the HIV/AIDS related information campaigns. Table A $2{ }^{15}$ shows 11 such variables found in the DHS core survey ( 6 common between males and females and 6 exclusive to males). When used as outcomes such attitudes provide grounds to empirically test the potential effects of HIV/AIDS-knowledge on risk-related behaviour. However, declared attitudes disclose 'subjective intention' as opposed to objective realized behaviour. Thus, estimating the causal effect from $\kappa$ on attitudes is a preliminary test on the effect that disseminated information may have had on individual's potential behaviour, while allowing for actual (ceteris paribus) HIV-status as the outcome is the objective measure of the effect of $\kappa$ (and therefore that of information campaigns) on realized behaviour. Table A2 also shows two variables that relate to the attitude that males may have with regards to women: it is often the case that males attitudes towards women (e.g., violence and abuse) can determine female's health status (see, for example, the WHO report on violence, WHO Fact Sheet N.239, 2000). The two variables (ATTWC1 and ATTWC2) in Table A2 aim at capturing the effects, if any, of information campaigns on male's changing attitudes towards women when such attitude may directly affect STD. The sample statistics in Table A2 shows some light with regards to the (unconditional) behaviour of the population: it is striking that only $14 \%$ of sexually active males ( $27 \%$ of sexually active female) use condoms regularly while (at least for males) the number of sex partners during the last calendar year was significantly larger than one.

\subsection{HIV-status}

The most important outcome variable of interest in our analysis is HIV-status. This outcome is obtained from at most 8,800 individuals who were randomly asked to provide blood for the purpose of HIV-testing. Table 1 show that only $70.3 \%$ of the initial 8,800 provide blood for the purpose of HIVtesting. Those who did not provide blood are divided into two groups: 1,429 who directly refuse voluntary

\footnotetext{
${ }^{14}$ We note that using the number of answers instead would lead to similar results but it would make the analysis more difficult since we would have to deal with more than 30 distinct dummies (see Table A1, Appendix A1).

${ }^{15}$ Table A2 shows the sample size for females to be 8,187 and not 8,195 as shown in Table A1. The samples displayed in Table A2 are the final samples (males and females) used in the causal analysis. The difference ( 8 females) in
} 
participation in the randomized testing, and 1,179 who refused to participate in the survey even before they were asked to provide blood for HIV-testing. ${ }^{16}$ The latter do not necessarily constitute sample selection bias with respect to the outcome HIV-status because their refusal is not as consequence of being asked for blood. On the other hand the first group (1,429 individuals) refused to participate in the HIV-test despite having answered to all questions in the core DHS: while core information from these individuals cannot be ignored we need to treat them as a selected sample when the outcome of interest is HIV-status (Section 5). Table 2 shows the distribution of the 8,800 units according to response behaviour, gender and HIV-status.

Table 2: Distribution of selected sample for HIV-testing (response and HIV-status by gender)

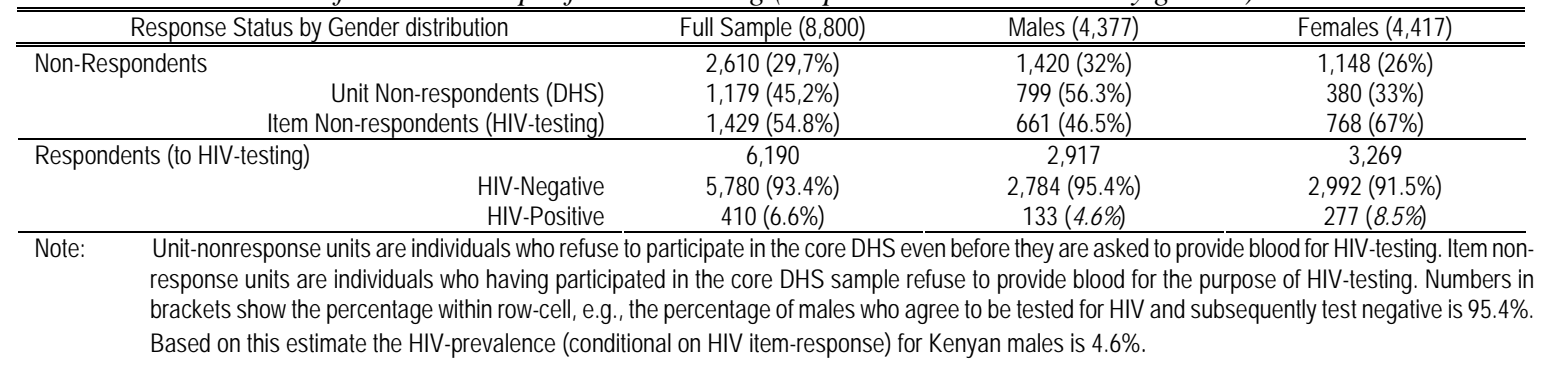

Conditional on HIV(-test)-response, Table 2 shows that the HIV-prevalence in Kenya in 2003 was $4.6 \%$ for males and $8.5 \%$ for females. However, the conditional assumption would imply allowing for testnonresponse to be treated as random nonresponse. Refusal to respond may be as consequence of HIV-status (e.g., those who know with certainty to be HIV-negative do not want to risk the potential effect of having a needle applied to them) and possibly also as consequence of HIV-knowledge. Under the assumption of random unit nonresponse with respect to HIV-status, we may ignore unit non-respondents and use the probability of item non-respondents to define a probabilistic worst case bound that may provide a more realistic picture of the HIV-prevalence in Kenya. Thus, allowing for bounding intervals the sample estimates suggest that HIV-prevalence for the population lays between $5.4 \%$ and $24.2 \%$. In the case of

sample size between Tables A1 and A2 results from dropping 8 females that displayed incomplete outcome information.

${ }^{16}$ That is, the 8,800 are initially randomly selected as the group of males and females that are later asked to participate in the core DHS sample. This guarantees that the 8,800 constitute a random selection from the population; the same would not be the case if selected after some may have refused to participate in the DHS survey since these would unquestionably lead to sample selection bias from those accepting to donate blood. However, some of the randomly 
males the bounding interval lays between $3.7 \%$ and $22.2 \%$ whereas female's HIV-prevalence is bounded between $6.9 \%$ and $25.9 \% .{ }^{17}$ Clearly the consequence of high nonresponse to HIV-testing leads to intervals that are too wide for us to use with regards to inference from the sample to the population: further weak data assumptions would be required in order to make these tractable for policy evaluation. However, Section 5 takes into account information from non-respondents to the HIV-test to adjust for potential selection bias when estimating the conditional causal effect from $\kappa$ to HIV-status.

\subsection{Covariates}

Finally, testing for the effect of HIV-knowledge on the selected outcomes (either HIV-status or HIV-related attitudes) requires controlling for potential confounding effects as a result of variables that may affect both the outcome of interest and/or the variable HIV-knowledge. Confounding effects are often controlled for using variables that relate to the demographic, social and economic characteristics of individuals in the sample. The DHS contains a large number of potential confounders and we take advantage of the rich data set thus allowing for an extensive set of covariates to enter our estimation procedure. Ideally all variables that enter the analysis to control for confounding effects should be causal to the outcome and, at the same time, maintain the principle of exogeneity with respect to the outcome. Table A3 (Appendix A) shows the set of covariates used in our causal analysis. These include socio-demographic variables (e.g., age, ethnicity, education, religion, etc.), socio-economic variables exclusive to each of the gender groups (e.g., attitude of males towards females, pregnancy status for females, etc.), variables relating exclusive to health related knowledge (e.g., knowledge of contraception, knowledge about other STD, etc.) and household variables (e.g., wealth classification for the household, rural versus urban location, land and/or household ownership, etc). We believe that such a selection provides a full information set thus

selected males and females decided not to participate in the survey (core DHS) and this indirectly affects the final sample size of individuals who are then 'asked' to become part of the randomized HIV-testing.

${ }^{17}$ Worst case bounds are based on the Bayesian partition. Let $\tau=1$ and $\tau=0$ indicate item response and item nonresponse, respectively. With this, the population HIV-prevalence may be explained as follows: $P(H I V=1)=P(H I V=1 \mid \tau=1) P(\tau=1)+P(H I V=1 \mid \tau=0) P(\tau=0)$. Using these partition and in the presence of non-negligent item non-response, all we know with respect to those who do not wish to provide blood is that the prevalence lies in the unit interval, i.e., $P(H I V=1 \mid \tau=0) \in[0,1]$. Allowing for the unknown measure to be $P(H I V=1 \mid \tau=0)=1$ and $P(H I V=1 \mid \tau=0)=0$ determines the upper and lower worst case bounds, 
allowing us to isolate the effects of the HIV-knowledge on particular outcomes. ${ }^{18}$ The last column in Table A3 shows a set of variables defined as 'instruments'. These variables are used at cluster level (see Section 4.1) to correct for possible endogeneity effects in the causal relation between HIV-knowledge and both behaviour attitudes and HIV-status, an issue that becomes the subject of subsequent sections below.

\section{The effect of HIV-knowledge on HIV-attitudes and behaviour}

\subsection{Instrumenting the variable knowledge and modelling HIV-related attitudes}

In the first part of our analysis we examine the effects of knowledge on individual's behaviour. We argue that an individual's HIV-status essentially depends on two sources: prudent HIV related behaviour and environmental factors. The latter may be considered as 'not under the direct control of the individual', e.g., HIV-prevalence (common to all in the same locality at any given point in time) or individual specific environments (e.g., becoming a subject of violence, infection from mother-to-child transmission, etc.) The implication is that even the most prudent person faces some risk. The 'prudent behaviour of individuals', on the other hand, can be thought as driven by two factors: acquired knowledge (information) and risk preferences. An individual with incomplete knowledge about HIV/AIDS may be unaware what type of 'prudent' behaviour may be required to reduce the risk of becoming HIV-positive at each and every risksituation: this may be the case even if the individual is infinitely risk averse. On the other hand, individuals differ with regards to risk preferences and rationally take risks.

Therefore this section aims at empirically testing the causal path between HIV-knowledge - as measured by $\kappa-$ and the outcomes in Table A2 each of which signals behaviour towards attitudes frequently targeted by information campaigns. The causal analysis controls for observed variability allowing for covariates as defined in Table A3. ${ }^{19}$ It is clear that 'declared attitudes' as described in Table A2

respectively. Worst case bounds could be further tightened using weak date driven assumptions as those implied by monotonicity and exclusions (see Manski, 1989, 1990 and reference therein for further details).

${ }^{18}$ For a full list (and descriptive statistics) of variables included in the DHS-2003 see the online DHS-2003 report at www.measuredhs.org.

${ }^{19}$ As with any other study at the microeconomic level, our aim is to control for all heterogeneity that may affect the outcomes in the population, be these 'declared attitudes' in the present section or 'HIV-status' in Section 5. It is our hope that observed sample variability provides an accurate control with regards to individual's idiosyncratic behaviour that may be related to the outcomes. Nevertheless, we cannot disregard the possibility that observed 
may not necessarily imply intended or actual behaviour, thus, this first step allows for the initial set of estimates to complement the finding in Section 5 below where the outcome of realized behaviour, that is HIV-status, becomes the subject of our empirical estimations.

Let $Y_{i}$ be the outcome of interest, i.e., any of the possible 11 attitudes in Table A2 and let $D_{i}$ stand for the HIV/AIDS knowledge, i.e., $\kappa_{i}$. We assume a linear relationship:

$$
Y_{i}=\alpha+\beta D_{i}+\gamma X_{i}+U_{i}
$$

where $X_{i}$ and $U_{i}$ are observable and unobservable characteristics, respectively. Estimation is complicated by potential correlation between $D$ and $U$. Individuals may have acquired knowledge because of certain factors that might also make them more inclined to display certain attitudes. Instrumental variables $Z$ can help to overcome this endogeneity problem. As discussed below, exposure to mass media at cluster level (i.e., using instruments defined according to geographical regions) is likely to have affected the individual's knowledge about HIV/AIDS while the individual as a single unit cannot possibly influence the average knowledge within his or her regional cluster, conditional on many characteristics $X$ as shown in Table A3.

Instead of estimating a linear model, we could also consider nonparametric estimation of the relationship between knowledge and attitudes. For identifying the entire relationship between $Y$ - binary for most of the outcomes in Table A2 - and D - the knowledge variable - one would need continuous instruments with large (i.e. infinite) support (see Haile and Tamer 2003 or Magnac and Maurin, 2006). Using instruments with limited support, some average aspects of the relationship can still be identified (see e.g. Frölich, 2007). Nevertheless, in this paper we restrict ourselves to the linear parametric model mainly for reasons of consistency with the approach in Section 5 where we will have to deal with the additional problems of potential reverse causality and the partially unobserved outcome variable HIV-status. Nonparametric identification for a binary outcome variable is much harder in such a setup and requires

confounders are absorbing some of the effect from unobserved variability. If this is the case, our estimates are still valid as long as the key 'treatment' under consideration is not itself picking up the effect of unobserved $3^{\text {rd }}$ variables. In the present section the use of instruments aim at controlling for such endogeneity problem. In Section 5 we will comment on the valid use of the confounders in Table A3. 
more exclusion restrictions and instrumental variables with large support that are not at our disposal. Thus, we confine our analysis to parametric identification throughout.

We estimate $\beta$ in equation (1) by linear IV estimation (i.e., 2SLS) under the assumption that $E[U \mid Z, X]=0$. The crucial assumption is that after we condition on $X$ the instrumental variables $Z$ do not affect the attitudes and behavioural outcomes directly. Instead, the instruments $Z$ should affect HIV-risk related behaviour and attitudes only indirectly by knowledge but not directly. We argue that exposure to mass-media channels such as radio, television and newspapers are valid instruments that affect knowledge directly. Likewise, declared direct exposure to information about condoms (or family planning) in the radio, television and newspapers provide similar direct effects on knowledge. Clearly, exposure to mass-media represents one of the information channels through which information campaigns aime at conveying knowledge about HIV/AIDS. At the same time, the probability that a single individual affects the disseminated information within such mass-median channels is very unlikely. Thus, such mass-media related variables would be ideal candidates for $Z$ if we assume (i) that individuals are passive recipients of the information from radio, television and newspapers and (ii) that such information arrives at individuals randomly: only under (i) and (ii) could we say that $E[U \mid Z, X]=0$ because the assumptions would imply that $Z$ is uncorrelated to the unobservable variability in $U$ while $Z$ directly affects the outcomes in Table $A 2$. The problem is that unobserved heterogeneity in $U$ is likely to affect both the outcomes in Table A2 (as well as the HIV-status of the individuals) and the individual's exposures to mass-media channels. For example, unobserved motivation may affect the individual's thirst for information and, at the same time, affect his or her attitudes (independent of his likeness for information) and HIV-status. To overcome this problem, we convert the variables 'exposure to mass-media channels' using the individual specific 'non-self and nonhousehold' cluster mean: this means that for each individual we measure the average exposure of all members in the individual's community excluding the actual exposure associated with both the individual and members of his or her own household. Table 3 shows sample statistics for each of the six measures of mass-media exposure allowing for the sample to be distributed according to 400 GPS-defined geographical areas in Kenya. The intuition in using the variables in Table 3 as instruments in the set $Z$ is now clear: all 
variables are based on information that may directly affect the knowledge of the individual (as intended by the information campaigns) but by construction these are all independent of $U$ at an individual level - e.g., variables in $Z$ are now independent of the individual's unobserved motivation - so that $E[U \mid Z, X]=0$ holds for the population. Finally, it is important to mention that the confounding variables in $X$ contain not only several socioeconomic characteristics (e.g., family composition, housing, employment status, wealth indicators including possession of radio and television) but also several other indicators of general attitudes and behaviour such as religion, smoking and alcohol drinking, ideal family size, etc. There are also several indicators of attitudes towards investments into health in general, e.g. if children are covered by mosquito nets, visits to doctors, vaccinations, body mass index of children, etc. To avoid confounding knowledge about HIV/AIDS with general knowledge we also condition on education and literacy and specific health knowledge, i.e. knowledge about contraceptives, family planning, STD, malaria, diarrhoea etc. Hence, conditional on socioeconomic characteristics, wealth, attitudes and behaviour in general, health investments indicators and knowledge about health in general, we assume that the effect of mass-media exposure on attitudes and behaviour is channelled via HIV/AIDS knowledge. In Section 5 we will be assuming that the entire effect of mass-media exposure on the true HIV-status is channelled via HIV/AIDS knowledge, i.e., the use of instruments is also pertinent in further estimation steps. ${ }^{20}$

\subsection{Empirical results}

The last column in Table A3 (Appendix A) shows the set of instruments to be used in the first step estimation of our Two Step Estimation procedure as described in Section 4.1. The instruments all refer to 'non-self regional cluster mean exposure to media information' in the form of radio (RAFRE), television (TVFRE) or newspapers (NWFRE): all variables are independent from individual's information and constructed at cluster level (see Section 4 above). We know from Kamali (2003) or Shanya (2005) that information campaigns were widely disseminated through media such as television, radio and newspapers

\footnotetext{
${ }^{20}$ It is important to notice that instruments that relate to cluster variables - e.g., the use of distance to a family planning clinic, number of pharmacies, distance to schooling centres, etc. - would also act as potential instruments for the treatment 'knowledge'. Unfortunately, information on public services at cluster level is not available for the DHS2003. This is not the case with other DHS sets - e.g., DHS data on Bangladesh, 1994-2004 - where cluster level information is readily available.
} 
or printed matter in general thus reinforcing our assumption that the instrumented variables in Table 3 picks up 'information campaigns knowledge' while the individual as a unit has not direct effect on such measures. ${ }^{21}$ Furthermore, we exploit variables that offer direct information (also measured at cluster level and independent from self-information) about exposure to items often specifically targeted by information campaigns, namely, average exposure of the males in the community to family planning in the radio, television or newspapers and-magazines, and average exposure of the females in the community to condom. $^{22}$ Table 3 shows the sample statistics for all 6 instruments considered by gender subgroups. Originally all 6 variables are given in terms of a binary indicator where 1 implies that the individual declares frequent exposure to a specific mass-media channel (e.g., the radio) or specific items in the massmedia (e.g., condom) and 0 implies no frequent or negligent exposure. When these 6 variables are based at the cluster level, they become mean values for the sample ranging in the $[0,1]$ interval.

\footnotetext{
${ }^{21}$ It may even be assumed that there is a certain degree of exogenous information exposure in countries such as Eastern Africa where being exposed to information is often a communal decision rather than the outcome of an isolated choice. This is direct consequence of the relatively low per capita number of radios and televisions in such economies. For example, according to United Nation Population statistics, in 2005 the estimates show that at most 103 per each 1000 inhabitants owned a radio-receiver whereas 26 per each 1000 inhabitants owned a television set (see www.populstat/info/Africa/kenyag.htm for further details).

${ }^{22}$ Information about exposure to 'family planning knowledge' based on mass-media is only asked to the males in the sample, whereas exposure to 'condom knowledge' based on mass-media is asked only to the females in the sample. Since we define these variables at cluster level we are able to associate each of the six variables to all in the sample irrespective of gender. However, as was the case with the cluster-based variables RAFRE, TVFRE and NWFRE, the individual specific cluster value is estimated excluding any other sample unit that declares to belong to the same household as the individual in question. This means that all variables in the IV-set as described in Table 3 are nonself and non-family related cluster means.
} 
Table 3: Instrumental variables: Cluster level based channels of information

\begin{tabular}{|c|c|c|c|c|}
\hline & Instruments by Gender distribution & Mnemonic & $\begin{array}{c}\text { Males } \\
(3,578) \\
\end{array}$ & $\begin{array}{c}\text { Females } \\
(8,187) \\
\end{array}$ \\
\hline \multicolumn{2}{|c|}{$\begin{array}{l}\text { Cluster mean frequent exposure to Radio } \\
\end{array}$} & RAFRE & $0.79(0.004)$ & $0.78(0.003)$ \\
\hline \multicolumn{2}{|c|}{ Cluster mean frequent exposure to Television } & TVFRE & $0.33(0.003)$ & $0.34(0.002)$ \\
\hline \multicolumn{2}{|c|}{ Cluster mean frequent exposure to newspapers/magazines } & NWFRE & $0.35(0.003)$ & $0.36(0.003)$ \\
\hline \multicolumn{2}{|c|}{ Cluster mean having heard about Condoms in the radio } & RAFCO & $0.65(0.004)$ & $0.64(0.003)$ \\
\hline \multicolumn{2}{|c|}{ Cluster mean having heard about Condoms in Television } & TVFCO & $0.38(0.003)$ & $0.38(0.003)$ \\
\hline \multicolumn{2}{|c|}{ Cluster mean having heard about Condoms in Newspapers-Magazines } & NWFCO & $0.44(0.005)$ & $0.43(0.003)$ \\
\hline \multicolumn{2}{|c|}{ Cluster mean having heard about Family Planning in the Radio } & RAFFP & $0.72(0.004)$ & $0.71(0.003)$ \\
\hline \multicolumn{2}{|c|}{$\begin{array}{l}\text { Cluster mean having heard about Family Planning in the Television } \\
\text { Cluster mean having heard about Family Planning in Newspapers-Magazines }\end{array}$} & TVFFP & $0.37(0.005)$ & $0.38(0.003)$ \\
\hline \multicolumn{2}{|c|}{ Cluster mean having heard about Family Planning in Newspapers-Magazines } & NWFFP & $0.36(0.004)$ & $0.36(0.003)$ \\
\hline Note: & \multicolumn{4}{|c|}{$\begin{array}{l}\text { All variables are mean cluster values for each individual independent from both the individual's answer and answers by other individuals in the same } \\
\text { household as the individual. The sample is such that each individual's mean is, on average, based on } 30 \text { individuals that belong to his(her) cluster but } \\
\text { are not in the same household: this applies to all } 9 \text { instrumental variables. An average close to zero implies the cluster to which the individual belongs } \\
\text { has low exposure to the mass-media item or actual knowledge on particular items via the pertinent mass-media channel. Alternatively, a mean value } \\
\text { close to } 1 \text { means that irrespective of the individual specific knowledge, the cluster to which the individual belongs is associated with high exposure } \\
\text { regarding that mass-media item. The original variable (in all cases) was a category that asked individuals to classify their 'exposure' between 'every } \\
\text { day', 'at least once a week',' 'less than once a moth', 'never' or 'missing/don't know'. Only a few individuals did not answer to some of the questions (for } \\
\text { any given question the recorded answers implied less than } 10 \text { missing answers for females and less than } 5 \text { for males). Missing values were imputed } \\
\text { with a } 0 \text { (no exposure) so that we would not loose their information in the survey (i.e., it is assumed that and ambiguous - 'don't know' - or a missing } \\
\text { answer reflects low exposure to the media channel since those exposed to information would not hesitate to answer the question. Notice that 'having } \\
\text { heard about family planning' or 'heard about condoms' is not used here as an indicator for 'knowledge' by cluster. The individuals in the cluster may or } \\
\text { may not know what family planning and condoms are: the key issue is the information campaigns have arrived to the district by means of observed } \\
\text { mass-media channels. }\end{array}$} \\
\hline
\end{tabular}

As expected, there is no statistical difference between genders with regards to 'average cluster exposures' to different mass-media communication channels, the reason being that the sample of males and females are all drawn from the same 400 clusters and the distribution of genders among clusters is similar. ${ }^{23}$ It is also clear from Table 3 that radio is the most commonly used communication tool in Kenya when compared to the dissemination effects of television or printed matter. Thus, exposure to media (and therefore, HIV/AIDS-related information campaigns) is more likely to be with regards to the use of radio. It is also the case that it is more likely that a radio is played at work places since it is a communication tool that disseminates information but is non-excludable from performing alternative tasks (e.g., driving a car, selling goods in the market, etc), while males are more likely to spend time outside the house (e.g., males spend time at work where a radio may be all day on for them to listen to). Thus, even if average exposure to the radio by cluster is estimated for both without gender differences, it may be the case that 'males' are

\footnotetext{
${ }^{23}$ Allowing for the joint sample of males $(3,578)$ and females $(8,187)$ each of the 400 clusters upon which the Kenyan population is divided by the DHS design contains approximately, 30 individual members that are distributed closely following the representation of the two genders, that is, the approximately 30 individuals per cluster are, on average, such that $25 \%$ of males and $75 \%$ of females.
} 
more likely to receive the effect of the item 'radio' exposure more than females. We account for this by estimating all outcomes of interests separating males and females into two distinct samples. ${ }^{24}$

The top part in Table 4 shows the result of using the 9 variables to instrument the measure $\kappa$ (see Figures 2 and 3) as the first step in the two step procedure where the final goal is to estimate the effect of knowledge $(D)$ on the various attitude items defined in Table A2. Based on the estimates from this first step estimation we see that for males in the population, cluster exposure to radio as well as both cluster exposure to family planning and condom advertisement in the radio are all significant at explaining $\kappa$ : the instrument 'cluster exposure to television' is also significant at explaining knowledge $\kappa$ for males but only weakly significant at a much lower p-value than other significant instruments. Except for the weakly significant instrument, all other coefficients suggest a positive causal relation between each of the instruments and the knowledge variable. Such evidence suggests that in the case of males, exposure to the radio has a significant effect at increasing their knowledge. ${ }^{25}$ The same conclusion can be drawn from Table 4 (first step) with regards to females and their cluster-based exposure to the item radio since it is also the case that exposure to radio positively and significantly affects female's knowledge $(\kappa)$. But moreover, being exposed to family planning and condom-advertisement through newspapers and magazines also significantly increases $\kappa$ for the females in the population. As was the case for males, television exposure (in this case based on cluster frequency exposure to the actual item) is significantly associated with lower values of knowledge $(\kappa)$, that is, for both genders the empirical evidence suggest the local (cluster-based) availability of televisions does not necessarily help to transfer the knowledge required to reduce the effects of the HIV/AIDS epidemic. Overall, we take the estimates in the first step of Table 4 as evidence to suggest the statistical validity of four instruments in the case of males and seven instruments in the case of

\footnotetext{
${ }^{24}$ In fact, when estimating the average exposure to the radio at the individual level we find that $89 \%$ of males declare frequent exposure to a radio and this compares to females whose answer implies that at most $74 \%$ are frequently expose to the radio. The difference $(15 \%)$ is statistically significant ( $t$-ratio $=21.2)$. However, difference to communication exposure between genders is not limited to that of radio exposure. Males are $10 \%$ more likely to be frequently exposed to TV than females and also $15 \%$ more likely to have frequent exposure to printed matter such as newspapers and magazines. The two probability differences are statistically significant.

${ }^{25}$ We notice that the actual measured (IRT based) $\kappa$ has an arbitrary value that goes from -2 to +2 in both the case of males and females. The actual 'value' is a ranking measure that defines the degree of knowledge relative to others in the sample. As the value $\kappa$ increases this implies more knowledge. Each of the exclusion restrictions is defined as a binary outcome with 1 associated with 'exposure to information': a positive coefficient in a regression where the
} 
females. ${ }^{26}$ The second step (second part in Table 4 ) shows the causal link between $\tilde{D}$ (i.e., the instrumented $\kappa$ using the corresponding valid instruments) and the different measures of 'behavioural attitudes': under the assumption of valid instruments the variable $\tilde{D}$ is exogenous for all the behavioural attitude outcomes $Y$ (see Section 4.1). The estimation is performed separately for each gender and allows for two different specifications: Model 1 estimates the conditional effect of $\tilde{D}$ on attitudes ignoring the effect from other sources of observed heterogeneity. Model 2 allows for possible confounding effects with variables in $X$ that control for demographic, social and general health effects obtained from answers to the core DHS. Allowing or not for confounding effects, the estimates are qualitatively very similar: the coefficient in the second part of Table 2 all show a positive relation and most show a statistically significant causal effect from $\tilde{D}$ to each of the variables considered to be indicators of behavioural attitudes. The exception in Table 4 is with respect to the outcome 'number of partners'. Based on the restricted model (Model 1) the estimates suggest that more knowledge $\kappa$ is statistically causal to an increase in the number of partners for both males and females: such evidence would not benefit the backing up of information campaigns. However, using the unrestricted version (Model 2) suggests that the initial significance of the variable knowledge $(\kappa)$ on the outcome 'number of partners' based on Model 1 was due to omitted variables bias: once confounding effects are accounted for the relation between knowledge $\kappa$ and number of partners still remains positive but it is no longer statistically significant. Other than the outcome 'number of partners', all other attitude related outcomes are positively enhanced by knowledge: both males and females show that knowledge increases the use of condoms, makes them agree with statements such as 'it is ok to talk about condoms on the radio (television or newspapers)', it becomes more likely for them to talk about HIV/AIDS with their partners and they are more likely to agree about teaching children about condom-use at school. Specifically for males, the effect of a good stock of knowledge is to reduce negative attitudes towards women, increases

instruments determine the variable $\kappa$ implies that 'more exposure' is associated with higher ranked positions in the measured $\kappa$ variable.

${ }^{26}$ The initial F-tests shown in Table 4 suggest that all instruments provide a jointly valid specification for the outcome knowledge $\kappa$ both in the case of males and females. However, we test the reduced form specification with 4 (6) instruments for males (females) to find that an F-test for the new specification rejects the initial unrestricted specification with the new F-test for the subgroup males (females) equal to $F=12.3$ (1.13). 
their chances of not being embarrassed when buying condoms and it is more like that they will know that condoms cannot be re-used.

In general it seems that Table 4 provides quantitative evidence that acquiring knowledge relative to HIV/AIDS induces the correct behaviour attitudes as intended by the information campaigns. Nevertheless, the goodness of fit test contrasting the two models per each outcome considered shows relatively poor fits (i.e., relative low $R^{2}$ ). Thus, despite the large numbers of confounding effects much remains to be explained with regards to what determines the attitude of individuals (e.g., time preferences, motivation, ability, etc). Our estimates simply suggest that 'at least' the knowledge $\tilde{D}$ remains statistically significant to explain individual's declared attitudes. We take this as evidence that the message from information campaigns has filtered through in the population such that relevant knowledge is positively associated with correctly declared attitudes and behaviour. 
Table 4: Two Step Estimation on the effect of HIV/AIDS knowledge on behaviour (by gender) ${ }^{27}$

Step 1: Dependent Variable is Knowledge measure

\begin{tabular}{|c|c|c|}
\hline Instruments & MALES & FEMALES \\
\hline Cluster mean RAFRE & $0.788^{* \star}(0.123)$ & $0.999 \star \star(0.078)$ \\
\hline Cluster mean TVFRE & $0.288(0.204)$ & $-0.239 * *(0.133)$ \\
\hline Cluster mean NPFRE & $0.052(0.215)$ & $0.354 * *(0.142) 0$ \\
\hline Cluster mean RA-FAMILY PLANNING(RADFP) & $0.412^{* \star}(0.074)$ & $0.125^{\star \star}(0.048)$ \\
\hline Cluster mean TV-FAMILY PLANNING (TVSFP/CD) & $-0.142^{\star}(0.094)$ & $0.073(0.062)$ \\
\hline Cluster mean NP-FAMILY PLANNING (NWPFP/CD) & $-0.021(0.089)$ & $0.013(0.059)$ \\
\hline Cluster mean RA-CONDOM (RADCD) & $0.665^{\star \star}(0.110)$ & $0.760^{* *}(0.070)$ \\
\hline Cluster mean TV-CONDOM (TVSCD & $0.104(0.146)$ & $0.053(0.095)$ \\
\hline Cluster mean NP-CONDOM (NWPCD) & $0.120(0.128)$ & $0.354^{\star \star}(0.085)$ \\
\hline Constant & $-1.50 *(0.056)$ & $-1.61^{* \star}(0.034)$ \\
\hline$R^{2}$ & 0.22 & 0.29 \\
\hline Joint $F$ test for the 9 instruments & $F_{(9,3568)}=114.00$ & $F_{(9,8177)}=364.4$ \\
\hline Number of observations & 3,578 & 8,187 \\
\hline
\end{tabular}

Step 2: Effect of instrumented knowledge ( $\tilde{D}$ : instrumented knowledge from Step 1) on selected outcomes

\begin{tabular}{|c|c|c|c|c|c|c|c|c|}
\hline \multirow{3}{*}{ Dep. Variables: Attitudes (Table A3) } & \multicolumn{4}{|c|}{ MALES } & \multicolumn{4}{|c|}{ FEMALES } \\
\hline & \multicolumn{2}{|c|}{ Model 1} & \multicolumn{2}{|c|}{ Model 2} & \multicolumn{2}{|c|}{ Model 1} & \multicolumn{2}{|c|}{ Model 2} \\
\hline & $\begin{array}{l}\text { Coeff. } \\
\text { (t-values) }\end{array}$ & $R^{2}$ & $\begin{array}{c}\text { Coeff. } \\
\text { (t- } \\
\text { values) }\end{array}$ & $R^{2}$ & $\begin{array}{l}\text { Coeff. } \\
\text { (t-values) }\end{array}$ & $R^{2}$ & $\begin{array}{c}\text { Coeff. } \\
\text { (t- } \\
\text { values) }\end{array}$ & $R^{2}$ \\
\hline $\begin{array}{l}\text { Dummy=1 if more than one sexual partner during last } \\
\text { calendar year (including marital spouses ) } \text { (1) }^{(1)}\end{array}$ & $\begin{array}{l}0.026^{*} \\
(0.014)\end{array}$ & $\leq 0.10$ & $\begin{array}{c}0.114 \\
(0.098)\end{array}$ & $\leq 0.10$ & $\begin{array}{l}0.006^{* *} \\
(0.002)\end{array}$ & $\leq 0.10$ & $\begin{array}{c}0.005 \\
(0.006)\end{array}$ & 0.12 \\
\hline $\begin{array}{l}\text { Dummy }=1 \text { if individual's common method of } \\
\text { contraception is the use of condom (2) }\end{array}$ & $\begin{array}{l}0.122 * * \\
(0.012)\end{array}$ & $\leq 0.10$ & $\begin{array}{c}0.092 \\
(0.077)\end{array}$ & 0.15 & $\begin{array}{l}0.229 * * \\
(0.008)\end{array}$ & $\leq 0.10$ & $\begin{array}{l}0.216^{* *} \\
(0.021)\end{array}$ & 0.12 \\
\hline $\begin{array}{l}\text { Dummy }=1 \text { if individual agrees that it is acceptable to } \\
\text { advertise condoms in the radio }\end{array}$ & $\begin{array}{l}0.226^{\star *} \\
(0.016)\end{array}$ & $\leq 0.10$ & $\begin{array}{l}0.443^{* *} \\
(0.106)\end{array}$ & $\leq 0.10$ & $\begin{array}{l}0.215^{* *} \\
(0.009)\end{array}$ & $\leq 0.10$ & $\begin{array}{l}0.219 * * \\
(0.021)\end{array}$ & 0.10 \\
\hline $\begin{array}{l}\text { Dummy }=1 \text { if individual agrees that it is acceptable to } \\
\text { advertise condoms in the television }\end{array}$ & $\begin{array}{l}0.214^{* *} \\
(0.016)\end{array}$ & $\leq 0.10$ & $\begin{array}{c}0.399 \\
(0.106)\end{array}$ & 0.10 & $\begin{array}{l}0.204^{* *} \\
(0.009)\end{array}$ & $\leq 0.10$ & $\begin{array}{l}0.192^{\star *} \\
(0.022)\end{array}$ & 0.10 \\
\hline $\begin{array}{l}\text { Dummy }=1 \text { if individual agrees that it is acceptable to } \\
\text { advertise condoms in newspapers/magazines }\end{array}$ & $\begin{array}{l}0.240^{* *} \\
(0.017)\end{array}$ & $\leq 0.10$ & $\begin{array}{l}0.426^{*} \\
(0.105)\end{array}$ & $\leq 0.10$ & $\begin{array}{l}0.217^{* *} \\
(0.009)\end{array}$ & $\leq 0.10$ & $\begin{array}{l}0.205^{\star *} \\
(0.022)\end{array}$ & 0.10 \\
\hline $\begin{array}{l}\text { Dummy }=1 \text { if individual agrees that it is acceptable to } \\
\text { teach children about condoms }\end{array}$ & $\begin{array}{l}0.229 * * \\
(0.018)\end{array}$ & $\leq 0.10$ & $\begin{array}{l}0.432^{*} \\
(0.120)\end{array}$ & $\leq 0.10$ & $\begin{array}{l}0.165^{* *} \\
(0.009)\end{array}$ & $\leq 0.10$ & $\begin{array}{l}0.191^{\star *} \\
(0.023)\end{array}$ & $\leq 0.10$ \\
\hline $\begin{array}{l}\text { Dummy }=1 \text { if individual declared to have discussed how } \\
\text { to avoid HIVIAIDS with partner' (3) }\end{array}$ & $\begin{array}{l}0.176^{\star *} \\
(0.020)\end{array}$ & $\leq 0.10$ & $\begin{array}{l}0.337^{* *} \\
(0.140)\end{array}$ & 0.24 & $\begin{array}{l}0.220^{* *} \\
(0.010)\end{array}$ & 0.10 & $\begin{array}{l}0.300^{* *} \\
(0.026)\end{array}$ & 0.22 \\
\hline
\end{tabular}

${ }^{27}$ Model 2 (Step 2) further includes the following variables: (MALES) age, education (reference group, no years of education), a dummy for 'currently attending education', dummy for the individual' originated from a rural area or a city area (reference: if origins are abroad), dummy for rural/urban location at present, dummy for 'migrated to the area during adulthood', dummy for protestant, muslim and no religion (reference: Catholic), dummy for knowledge of modern contraceptive methods, dummy for knowledge of women's obulatory cycle, dummy for knowledge about women's potential to get pregnant if breastfeeding, dummy for how to treat diarrheic problems with children, dummy for employment at present, dummy to indicate that male have the final say in terms of buying household goods, visits in the household and/or health issues in the household, dummy for water arrives directly to the household by modern methods, dummy for household has own toilet facilities, dummy for household has a fridge, dummy for household owns a bicycle, dummy for household owns a motor-vehicle, dummy for household owns a linetelephone, dummy for household owns a television, dummy for household owns a radio, dummy for interviewer sees household half dilapidated, dummy for household ownership, variable for wealth quantile (5 categories), household size, per capita number of bed-nets and per capita number of rooms in the household, ideal number of boys he wishes to have, ideal number of girls he wishes to have. (FEMALES): All the same variables as males except for 'dummy for knowledge of women's obulatory cycle, dummy for knowledge about women's potential to get pregnant even if breastfeeding'. Furthermore female's information set includes dummy for 'female is head of household', dummy if 'she is head of household', dummy for 'newly born in last calendar year', dummy for 'now pregnant', variable for 'age when she first became mother' and information about the husband if the outcome variable relates to 'in a partnership'. See Table A3 in Appendix A for the source of information and further details. ${ }^{(1)}$ Applies only if individual has at least one partner during the last calendar year. ${ }^{(2)}$ Applies to all that have already started their sexual live. ${ }^{(3)}$ Applies to individuals that have a permanent partner at the time of the survey. First Stage estimation: the rows show the estimated coefficients from a linear probability model using distinct models by gender. Second step estimation: the rows show the distinct outcome variable (attitudes) and the estimates are the coefficients associated with the instrumented variable $\tilde{D}$ that was estimated in Step 1 . Model 1 includes only a constant and the instrumented variable $\tilde{D}$. Model 2 includes confounding effects $X$ as explained in the table. Bold and italic indicates statistical significance at $5 \%$ level or more (two stars) or at least at $10 \%$ level (one star) 
(Exclusive to Males)

Dummy $=1$ if the male declares to agree with the statement 'women have right ask man to put a condom' Dummy $=1$ if the male declares to agree with the statement 'contraception is not just women's business' Dummy $=1$ if the responding male declares no in the statement 'it is embarrassing to buy condoms' Dummy $=1$ if the responding male disagrees with the

statement 'condoms can be re-used if washed after use'

\begin{tabular}{|c|c|c|c|c|c|c|}
\hline $\begin{array}{l}0.185^{\star *} \\
(0.015)\end{array}$ & $\leq 0.10$ & $\begin{array}{l}0.234^{* *} \\
(0.104)\end{array}$ & 0.10 & -- & -- & -- \\
\hline $\begin{array}{l}0.181^{* *} \\
(0.017)\end{array}$ & $\leq 0.10$ & $\begin{array}{c}-0.003 \\
(0.097)\end{array}$ & 0.16 & -- & -- & -- \\
\hline $\begin{array}{l}0.184^{* *} \\
(0.017)\end{array}$ & $\leq 0.10$ & $\begin{array}{l}0.491^{* *} \\
(0.124)\end{array}$ & $\leq 0.10$ & -- & -- & -- \\
\hline $\begin{array}{l}0.377^{\star *} \\
(0.015)\end{array}$ & 0.10 & $\begin{array}{l}0.499 * * \\
(0.108)\end{array}$ & 0.17 & -- & -- & -- \\
\hline
\end{tabular}

One problem is that 'declared' attitudes may not necessarily reflect actual realized behavioural. If 'declared' and 'actual' attitudes correspond this implies that a correct stock of knowledge helps reduce the chances of becoming HIV-positive. Thus, we should observe a causal relation between $\kappa$ (or its instrumented counterpart) and HIV-status with high $\kappa$ significantly associated with a negative HIV-status. Such evidence would support the suggestion that 'information campaigns' modify behaviour translating into a lower HIV-prevalence in the population.

\section{$5 \quad$ Endogeneity, selection bias and HIV-status}

\subsection{Modelling the effect of knowledge on HIV-status with a self-selected sample}

Following from the results in Table 4, the next step is to specify and estimate a model for the effect of knowledge on HIV-status. In addition to the endogeneity concern due to confounding by third variables as in the previous section, two additional problems arise here: First, any correlation between knowledge and HIV-status may have been driven by reverse causality. Second, the HIV-status is observed only for those individuals who accepted to take part in HIV testing. As regards the first problem, with a single cross section, and, therefore, unable to observe how HIV/AIDS-knowledge varied over time, we cannot identify if HIV-status came before HIV/AIDS-knowledge or, alternatively, the reverse causal path is the correct one. Nevertheless, this problem should not stop us from using such wealth of data as that provided by the DHS. Instead, we aim at estimating the effect of knowledge $(\kappa)$ on HIV-status - objectively measured experimenting with sub-samples that may potentially differ according how knowledgeable individuals might be with regards to their actual HIV-status. To show the problem of reverse causality we let $H_{i}$ be the 
HIV-status of individuals ( 0 if negative and 1 if positive) and let $D_{i}$ be an indicator of health knowledge such that $D=D(\kappa)$ still applies for each $i \in n$. Consider a model

$$
\begin{aligned}
& H=\eta(B, D, W) \\
& D=\varsigma(N, H, Q) .
\end{aligned}
$$

where $B_{i}$ and $N_{i}$ are observed covariates and $W_{i}$ and $Q_{i}$ are unobservable covariates. Clearly, the set up in (2) differs from that in (1) in that we now allow for reverse causality between the two outcomes. Estimates in Section 4.1 rightly assumed that the stock of knowledge $D$ should have been acquired before declaring a particular attitude at the spot of being asked the attitude question by the interviewer. ${ }^{28}$ On the other hand, when estimating the effect of HIV/AIDS-knowledge on HIV-status we have to consider the possibility of reverse causality, that is, that awareness of oneself being HIV positive (e.g. due to routine testing during pregnancy) may induce this person to acquire knowledge on HIV, AIDS and treatment possibilities. Both mechanisms might be present at the same time. For some individuals knowledge about their HIV-status may have led them to acquire or ignore knowledge, whereas for other individuals knowledge may have had a causal impact on HIV status via changes in behaviour. Ignoring the possibility of reversed causality may lead to endogeneity and therefore spurious estimates.

Clearly, the use of information over time is often the adequate tool to solve reverse causality, but the lack of panel structure in our case precludes such a dynamic stance. One possible strategy is to use subsamples from the data that may differ with regards to knowledge about their true HIV-status. Sub-division of the surveyed individuals among such sub-samples requires further use of information in the data. We know that there is only one single method to learn about HIV-status and that is with a blood test. We recall that when individuals in the DHS are asked to provide a blood test they are not asked to declare their HIVstatus and they are told that the result of the test will not be passed on to them. However, in the process of

${ }^{28}$ For example, assume someone is interviewed in April 2003: it would be difficult to argue that a declaration on the day of the interview of 'using condoms regularly' causes the stock of knowledge $(\kappa)$ declared also on that same day. Of course, it has to be assumed that the actual questionnaire is not dynamically inducing knowledge to the individual as the individual answers the questions. It may also be that the respondent wants to satisfy the interviewer by correctly answering with affirmative questions according to expectations. We assume, however, that such affirmative questions would be dictated by what is expected of the respondent who may have learned such expectations as result of information campaigns. Thus, this would simply be a case where information campaigns 
answering to DHS questionnaire, respondents are asked to declare if they have ever undergone a HIV test. ${ }^{29}$ It may be argued that individuals who declare to have undergone a formal HIV-test are more likely to be aware of their true HIV-status (negative or positive) than those who declare to have never had the formal blood test. If so, reverse causality (from $H$ to $D$ ) is potentially a bigger concern for those who declare to have had a HIV-test. Based on these arguments we could eliminate those who declare to have had an HIVtest (i.e., individuals who are more likely to be objectively associated with reverse causality irrespective of their HIV results in the DHS) and estimate the causal path from $H$ to $D$ by focusing on the sub-sample that objectively ignores their true HIV-status, i.e., individuals who declare to have never had an HIV-test at the time of the survey. The problem, of course, is that when we eliminate those who have had an HIV-test we may be dropping the 'risky' set from the population, or even those who are more cautious in the population and take the test as consequence of their innate attitude, or both. In general, in the event that our assumption of reverse causality is incorrect, eliminating those who declared to have had a blood test could bias our estimates in the direction of unobserved heterogeneity (e.g., we may be selecting on low risk behaviour if those eliminated are more risky than the average in the population). ${ }^{30}$

The alternative estimation procedure to that of eliminating individuals who declare to have had an HIV-test is to use the complete sample under the assumption that reverse causality, if present, does not affect our estimates significantly. This would imply using the full set of individuals (3,578 males and 8,189 females) that we know are representative of the Kenyan population. Doing so, we can then infer from the sample to the population for the purpose of policy advice. In order to provide a full picture of the causal path from knowledge to objective HIV-status our estimates provide, compare and contrast the two estimation procedures. We start presenting the results in Table 5 that compares sample statistics between individuals who declare to have undergone an HIV-test against those who declare never to have taken an HIV-test. The selected variables allow for key socio-demographic indicators (age, education, religion,

affects attitudes declared without necessarily modifying behaviour, a possible outcome that we take fully into account in our estimation framework (see Section 4.1).

${ }^{29}$ The precise question (for both genders) is "I do not want to know the results, but have you ever been tested to see if you have the AIDS virus?"

${ }^{30}$ Other concerns arise. Even without the objective information from a HIV-test individuals may be relatively well aware of their HIV-status, for example, as result of objective knowledge about their sex-partner's HIV-status. Thus, 
wealth and urbanization), indicators of risk factors (number of partners and use of condoms), HIV/AIDS knowledge $(\kappa)$ and HIV-status (based on the DHS testing).

Table 5: Descriptive statistics comparing HIV-tested against non-HIV tested (by gender)

\begin{tabular}{|c|c|c|c|c|}
\hline & \multicolumn{2}{|c|}{ MALES $(3,578)$} & \multicolumn{2}{|c|}{ FEMALES $(8,187)$} \\
\hline & $\begin{array}{l}\text { Have had a HIV-test } \\
\qquad(n=624)\end{array}$ & $\begin{array}{l}\text { Have not had an HIV- } \\
\text { test }(n=2,954)\end{array}$ & $\begin{array}{l}\text { Have had a HIV-test } \\
\qquad(n=1,384)\end{array}$ & $\begin{array}{l}\text { Have not had an HIV-test } \\
\qquad(n=6,803)\end{array}$ \\
\hline AGE & $31.7(0.4)$ & $29.5(0.21)$ & $29.0(0.22)$ & $28.5(0.12)$ \\
\hline \multicolumn{5}{|l|}{ EDUCATION } \\
\hline Not completed primary & 6.9 & 8.6 & 12.0 & 16.5 \\
\hline Has schooling at most up to primary & 41.2 & 56.4 & 39.7 & 55.8 \\
\hline Has some or completed secondary schooling & 28.2 & 27.0 & 32.0 & 22.4 \\
\hline Has schooling beyond secondary & 23.7 & 8.1 & 16.3 & 5.2 \\
\hline \multicolumn{5}{|l|}{ RELIGION } \\
\hline Catholic & 26.8 & 25.3 & 25.9 & 22.9 \\
\hline Protestant & 55.3 & 57.9 & 63.9 & 61.1 \\
\hline Muslim & 11.4 & 10.5 & 6.9 & 13.7 \\
\hline No religion & 5.6 & 6.2 & 2.5 & 1.9 \\
\hline \multicolumn{5}{|l|}{ WEALTH INDEX } \\
\hline Poorest & 11.7 & 15.8 & 10.3 & 18.1 \\
\hline Next poorest & 10.4 & 16.6 & 10.6 & 17.0 \\
\hline Middle & 12.3 & 18.2 & 13.9 & 17.5 \\
\hline Upper middle & 17.5 & 21.8 & 17.3 & 19.4 \\
\hline Richest & 47.9 & 27.6 & 47.8 & 27.9 \\
\hline \multicolumn{5}{|l|}{ DEGREE OF URBANIZATON } \\
\hline Urban area & 53.2 & 71 & 52.0 & 69.4 \\
\hline Rural area & 46.8 & 29 & 48.0 & 30.6 \\
\hline $\begin{array}{l}\text { Average number of sex partners during last } \\
\text { calendar year (1) }\end{array}$ & $1.23(0.044)$ & $1.25(0.02)$ & $1.03(0.007)$ & $1.03(0.023)$ \\
\hline Declares to use condoms regularly (2) & $16.3(1.5)$ & $13.9(0.7)$ & $32.7(1.3)$ & $26.0(0.6)$ \\
\hline $\begin{array}{l}\text { Percentage in the top centile in terms of } \\
\text { HIVIAIDS knowledge }(\kappa)^{(3)}\end{array}$ & 84 units = $13.46(1.4)$ & 295 units $=9.98(0.5)$ & 191 units = $13.8(0.9)$ & 644 units $=9.5(0.4)$ \\
\hline Probability of HIV-positive ${ }^{(4)}$ & $5.5(0.8)$ & $4.1(0.3)$ & $11.01(1.4)$ & $7.8(0.5)$ \\
\hline \multicolumn{5}{|c|}{$\begin{array}{l}\text { See Table A3 in Appendix A for the source of information and further details. }{ }^{(1)} \text { Applies only to individuals with at least one partner during the last } \\
\text { calendar year. (2) Applies to all that declare to have already debuted in their sexual live. }{ }^{(3)} \text { The estimate shows the within HIV-tested subgroup } \\
\text { percentage with knowledge such that their IRT measure } \kappa \text { is in the top } 90^{\text {th }} \text { percentile of the } \kappa \text { knowledge distribution. }{ }^{\left({ }^{4}\right)} \text { The percentage is based on } \\
\text { the sample that having being selected for HIV-randomized testing does in fact accept to be tested }(2,917 \text { males and } 3,273 \text { females: see Table } 2) \text {. } \\
\text { Bracketed numbers show sample standard errors for the continuous variables or for the binary outcomes whose estimated percentages are based on } \\
\text { restricted samples. For easier reading of the table, probability estimates without bracketed standard errors are based on percentages from binary }\end{array}$} \\
\hline
\end{tabular}

The variables education and wealth show that relative to the non-tested, those who claim to have had an HIV-test are more likely to have education beyond high school and are also more likely to belong to the wealthier groups in society. These estimates point to the predictions drawn from the Grossman model suggesting that more education may induce better understanding of health knowledge and therefore an increase in prevention by testing. Likewise, those with wealth are more likely to afford the best treatment

even if our assumption about reverse causality is correct, eliminating those who have had a test reduces those who may cause reverse causality, but may not necessarily eliminate all that cause the reverse causality problem. 
(in the event of infection) so that for the wealthy delaying diagnoses leads to a higher cost, e.g., if an HIVpositive individual does not get treatment the effect of lost productivity as result of morbidity is higher for the wealthier than for those who may not even have regular employment (see Grossman, 1972, 1999 and related literature for the predictions of the health capital model). Alternative explanations to the relation between testing and higher socio-economic standing can also be found from the point of view of related but unobservable variation, e.g., unrelated medical care demand or work requirements. ${ }^{31}$ But Table 5 also shows that those who declare having been tested are associated with higher knowledge: the top deciles in the distribution of $\kappa$-knowledge is such that it holds higher numbers of HIV-tested individuals than non-HIVtested with $2.4 \%$-points more in case of males and $4.3 \%$-points more in the case of females. In both cases the difference is statistically significant. Better (or more) knowledge among those who have undergone the HIV-test may be thought as possible evidence that such group can provide endogeneity problems as consequence of reverse causality, specially since those who declare having undergone an HIV-test show evidence of a HIV-prevalence significantly higher than the HIV-prevalence recorded among the sub-group declaring never to have undergone an HIV-test. ${ }^{32}$ In total, there are 2,008 individuals who declare to have had an HIV-test (624 males and 1,384 females). Table 6 below is analogous to Table 2 (see Section 4.1) but refers to the sub-sample without the 2,008 individual for whom we can suspect that reverse causality may be present. We will estimate the conditional relation between knowledge and HIV-status, for males and females separately, using both the units implied by Table 2 (7,621 when we exclude the unit nonrespondents) and those implied by Table 6 (6,303 also excluding the unit non-respondents).

\footnotetext{
${ }^{31}$ More educated and/or wealthier individuals are more likely to demand medical procedures that involve the possibility of blood testing (e.g., it has become common procedure to perform blood tests to find out about HIV status and Hepatitis before major operations). Likewise, blood donation also requires testing for HIV and other contagious diseases with blood donation more likely to be from those who are not at the lower end of the wealth distribution. Finally, in SSA it has become common to provide the results of an HIV-test before the employer offers the vacancy to a new potential employee while regular contractual employment is often more associated with higher educational achievements.

${ }^{32}$ That is, other than that anonymously performed by the DHS from which individuals will not learn their HIV-status.
} 
Table 6: The sub-sample of individuals who do not know their HIV status

\begin{tabular}{|c|c|c|c|}
\hline Response Status by Gender distribution & "Full Sample $(7,488)$ & Males $(3,753)$ & Females $(3,735)$ \\
\hline $\begin{array}{r}\text { Unit Non-respondents (DHS) } \\
\text { Item Non-respondents (HIV-testing) }\end{array}$ & $\begin{array}{l}2,330(31.1 \%) \\
1,185(50.9 \%) \\
1,145(49.1 \%)\end{array}$ & $\begin{array}{l}1,328(35.4) \\
799(60.2 \%) \\
529(39.8 \%)\end{array}$ & $\begin{array}{c}1,002(26.8 \%) \\
376(38.0 \%) \\
626(62.5 \%)\end{array}$ \\
\hline Respondents (to HIV-testing) & $\begin{array}{c}5,158 \\
4,835(93.7 \%) \\
323(6.3 \%)\end{array}$ & $\begin{array}{c}2,425 \\
2,320(95.7 \%) \\
105(4.3 \%)\end{array}$ & $\begin{array}{c}2,733 \\
2,515(92.0 \%) \\
218(7.8 \%)\end{array}$ \\
\hline
\end{tabular}

Allowing for the full sample implies that we have 4,377 males initially selected for the randomized test and 4,423 females (see Table 2). Based on the selected sample from Table 6 the two figures drop to 3,753 and 3,735 for males and females, respectively. Both sets of units, independently for males and females, provide the basis to estimate the causal effects from knowledge $(D)$ on HIV-status $(H)$ as shown in Table 7 (see Section 5.2 below).

Before estimation takes place, however, both Tables 2 and 6 already point out the second problem in estimating the effects of knowledge $(D)$ on HIV-status $(H)$ since not all of those who have been randomly selected for HIV-testing accepted to be part of the randomized test. There is no reason to believe that unit non-response to the DHS core questionnaire relates to HIV-status so we do not need to take into account the induced non-response error that such non-response may imply. However, non-respondents to the HIV-test (who have nevertheless answered the DHS core questionnaire) may be a selective sample whose response behaviour is driven by HIV/AIDS-knowledge. Table 2 shows that a total of 661 males and 770 females refuse to be part of the HIV-testing proposed to them by the DHS designers. Likewise, Table 2 shows that once we eliminate those that may be thought more likely to cause reverse causality the totals drop to 529 and 616 for males and females, respectively. Based on these figures, item-nonresponse for the complete sample (selected sample) amounts to $18.4 \%$ (17.9\%) for males and $19.0 \%(18.4 \%)$ for females. Ignoring these individuals may lead to biased estimates on the effect of knowledge on HIV-status. Thus, we allow for their observed information to enter into our estimation procedure using a two part model where the first part estimates the effect of selection and the second part introduces the selection term in order to control for possible selection bias.

Besides considering the possibility of reverse causality, other endogeneity problems may arise as a result of unobserved variability that may associate the error terms $W$ and $Q$ in (2). For example, 
unobserved variables such as motivation, ability, risk factors, etc., may determine both knowledge and HIVstatus. Instrumenting knowledge follows the same steps as in Section 4.2 and the same set of significant instruments as the ones defined in Table 4: the resulting variable $(\tilde{D})$ determines the causal effect from knowledge to HIV-status in what is then defined to be a three part model, i.e., instrumentation, selection and outcome. Let utility and preference (determined by observed variability) establish a latent process for the two outcomes in (2) such that $D^{*}$ and $H^{*}$ are the unobserved (to the econometrician) outcomes that determine $D$ and $H$, respectively. Furthermore, let $\delta=1$ if randomly selected individuals accept to donate blood for HIV-testing and $\delta=0$ otherwise. Let $\mathrm{E}$ define a set of covariates that determines the response behaviour in the sample $(\delta)$ without affecting the outcome $(H)$, i.e., the variables in $\mathrm{E}$ are identifying exclusion in the selection process. Together with (2) the following assumptions apply:

Let $\quad N=[Z, B]$ where $\quad \mathrm{z} \in Z \subseteq \mathbb{R}^{p}, b \in B \subseteq \mathbb{R}^{s}$

Assumption.1: The selected sample implies no reverse causality

$$
D=\varsigma(Z, B, H, Q)=\varsigma(Z, B, Q)
$$

Assumption.2: The instruments $Z$ imply exogeneity from $D$ to $H \mid X$

$$
(W, Q) \perp Z \mid X \quad \text { and } \quad(\varepsilon, Q) \perp Z \mid X \quad \text { where } \quad \varepsilon \sim N(0,1)
$$

Assumption.3: The exclusions E allow identification under selection $\mid X$

Using Assumptions 1 to 3 the following framework explains our estimation and identification conditions:

$$
\begin{aligned}
& D^{*}=\left(B, Z, \alpha_{D} ; Q\right) \text { where } D=I\left(D^{*} \geq 0\right) \\
& \text { and } \\
& \qquad \begin{array}{l}
\delta^{*}=\delta\left(E, B, D, \alpha_{\delta} ; \varepsilon\right) \quad \text { where } \delta=I\left(\delta^{*} \geq 0\right) \\
\Rightarrow \\
H^{*}=\varsigma\left(B, D, \alpha_{H} ; W\right) \quad \text { where } \delta H=\delta I\left(H^{*} \geq 0\right)
\end{array}
\end{aligned}
$$




\section{$5.2 \quad$ Empirical results}

We estimate a three part model using the sub-samples of males and females as described in Table 2 and Table 6, i.e., allowing for the full sample and for a selected sample that may possibly suffer from less problems regarding reverse causality under the assumptions discussed in Section 5.1. In both cases we distinguish between males and females, and in both cases the first part of the estimation process implies instrumenting the variable knowledge as described in Section 4.2. ${ }^{33}$ In the second part of the estimation process the corresponding samples are used to estimate the selection equation whereas the outcome equation is based on the restricted samples that provide blood for HIV-testing. ${ }^{34}$ In order to identify the effect of selection (refusal or acceptance to be tested for HIV) on HIV-status we must come up with variables that affect the selection process $(\delta)$ but should not have an effect on the HIV-status $(H)$. The DHS provides information (in the form of indicators) on the interviewer. ${ }^{35}$ Clearly, although the characteristics of the interviewer who works for the DHS - e.g., his(her) motivation, ability, etc. - might affect the response behaviour of surveyed individuals, the interviewers are almost certainly independent of the HIV-status of these same surveyed individuals. Thus, we use the interviewers coding identifier as indicators that describe the set of variables in E. These identifiers control for the response behaviour of surveyed respondents confident that conditional on observed characteristics B such coding identifiers can explain $\delta$ but are clearly excluded from explaining the outcome HIV-status. The set $\mathrm{E}$ is used to estimate the Mill's ratio for selection correction.

One of the main routes of HIV-transmission is by means of sexual intercourse. We know that information campaigns intensely try to affect the sexual behaviour of individuals. Knowledge will be affected by these campaigns but not all individuals in the population will have been exposed to the campaigns 'before' starting their sexual life. Clearly, it would be of great benefit to our analysis if, alongside the knowledge variable $\kappa$, we could introduce an indicator that picks up the direct effect with

\footnotetext{
${ }^{33}$ We omit the results since these are similar to those defined in Step 1, Table 4.

${ }^{34}$ Separating by gender, it implies that the first step takes into account all the units initially selected for the randomized HIV-test except, of course, unit non-respondents. Thus, using the complete sample we have 3,758 males and 4,043 females (Table 2). Alternatively, using the selected sample we have 2,954 males and 3,359 females (Table 6).

${ }^{35}$ There are 81 DHS officers who interview all 8,187 females and 44 interviewers who interview the 3,578 males. The correlation between the DHS interviewers and the 400 clusters is low $(0.04$ and 0.03 for males and females,
} 
respect to the timing of the information campaigns relative to the respondent's sexual behaviour. Ignoring such type of indicators is analogous to treating all survey respondents as equals concerning the interaction between exposure to the epidemic and exposure to the information campaigns. Clearly this would be wrong because at any given point in time (e.g., in 2003) a cross-section reflects the interaction of many cohorts that faced different exposures to the epidemic when becoming sexually active as well as diverging with respect to the exposure of information campaigns at the time of their sexual debut. The DHS contains information on the 'age at which individuals first had sexual intercourse'. Clearly, introducing such variable (i.e., age of sexual debut) as exogenous variation would be questionable since 'age of sexual debut' is unquestionably dictated by unobserved variability that may not necessarily be picked up by the set of covariates (see Table 3A, Appendix A). For example, 'age of sexual debut' may explain levels of risk aversion, motivation and other idiosyncratic preferences that directly determine the HIV-status of individuals. Instead, we use a similar modelling strategy as that employed in deWalque (2007) where the age of 15 is taken as the benchmark age that reflects the age for the start of sexual life in Sub-Sahran Africa and combine it with the following fact: the first intensive information campaigns in Kenya started exactly on the $25^{\text {th }}$ of November, 1999 (see Shanya, 2005). To control for the time effects of information campaigns (alongside the Knowledge variable $\kappa$ ) we define a variable IDIC that equals 1 if the individual was 14 or younger in November 1999, and 0 otherwise. ${ }^{36}$ Given that the variable IDIC is purely based on the birth year of the individual it is by default exogenous and clearly absent from possible endogeneity effects. At the same time it is a variable that makes full reference to the date ' $25^{\text {th }}$ of November, 1999' since it is binary with reference to the age of the individual at this particular date. Thus, the variable IDIC is capable of exogenously capturing the timing of information campaigns on HIV-status. In the event that the indicator has explanatory power we would expect that the variable (IDIC) is inversely causal to the outcome HIV-

respectively) and not statistically significant. Thus, we are confident that interviewers are randomized over the country as it should be so that interviewers' bias did not affect the quality of the survey.

${ }^{36}$ The DHS-2003 is informative with regards to both the birth year and the month of birth. Therefore we know with precision if individuals were born before $1^{\text {st }}$ of December 1999 or otherwise. Since the information campaigns were first intensely introduced on the $25^{\text {th }}$ of December 1999 we allow for these to affect the sexual behaviour of those who were still 14 at that point, i.e., those born in December 1984 and thereafter. 
status. Table 7 provides some summary statistics with respect to the variable IDIC comparing the sample according to gender sub-groups.

Table 7: Descriptive statistics comparing IDIC $=1$ against ICID $=0$ (by gender)

\begin{tabular}{|c|c|c|c|c|}
\hline COMPLETE SAMPLE (see Table 2) & \multicolumn{2}{|c|}{ MALES $(3,578)$} & \multicolumn{2}{|c|}{ FEMALES $(4,037)$} \\
\hline & $\begin{array}{l}\text { Age } 15 \text { or older before } \\
\text { the first intensive } \\
\text { information campaigns } \\
(\text { IDIC=0) } \\
(n=2,981)\end{array}$ & $\begin{array}{c}\text { Age } 14 \text { or younger } \\
\text { before the first intensive } \\
\text { information campaigns } \\
(\text { IDIC=1) } \\
(n=597) \\
\end{array}$ & $\begin{array}{l}\text { Age } 15 \text { or older before } \\
\text { the first intensive } \\
\text { information campaigns } \\
(\text { IDIC=0) } \\
(n=3,406)\end{array}$ & $\begin{array}{l}\text { Age } 14 \text { or younger before } \\
\text { the first intensive } \\
\text { information campaigns } \\
(\text { IDIC=1) } \\
(n=631) \\
\end{array}$ \\
\hline AGE & $32.50(10.1)$ & $16.8(1.01)$ & $30.8(8.56)$ & $16.8(1.09)$ \\
\hline $\begin{array}{l}\text { Percentage in the top centile in terms of } \\
\text { HIVIAIDS knowledge }(\kappa)^{(1)} \\
\text { HIV }\end{array}$ & $13.9 \%$ & $10.1 \%$ & $10.6 \%$ & $10.2 \%$ \\
\hline Non-response to HIV-testing & $16.0 \%$ & $14.7 \%$ & $19.1 \%$ & $18.7 \%$ \\
\hline Response to HIV-testing & $84.0 \%$ & $85.3 \%$ & $80.9 \%$ & $81.3 \%$ \\
\hline Probability of HIV-positive (2) & $5.4 \%$ & $0.79 \%$ & $9.54 \%$ & $2.73 \%$ \\
\hline \multirow[t]{2}{*}{ SELECTED SAMPLE (see Table 6) } & \multicolumn{2}{|c|}{ MALES $(2,954)$} & \multicolumn{2}{|c|}{ FEMALES $(3,349)$} \\
\hline & $\begin{array}{l}\text { Age } 15 \text { or older before } \\
\text { the first intensive } \\
\text { information campaigns } \\
(\text { IDIC=0) } \\
(n=2,395)\end{array}$ & $\begin{array}{c}\text { Age } 14 \text { or younger } \\
\text { before the first intensive } \\
\text { information campaigns } \\
(\text { IDIC=1) } \\
(n=559) \\
\end{array}$ & $\begin{array}{l}\text { Age } 15 \text { or older before } \\
\text { the first intensive } \\
\text { information campaigns } \\
(\text { IDIC=0) } \\
(n=2,761)\end{array}$ & $\begin{array}{l}\text { Age } 14 \text { or younger before } \\
\text { the first intensive } \\
\text { information campaigns } \\
(\text { IDIC=1) } \\
(n=588) \\
\end{array}$ \\
\hline AGE & $32.5(10.28)$ & $16.8(1.00)$ & $30.97(8.71)$ & $16.77(1.09)$ \\
\hline $\begin{array}{l}\text { Percentage in the top centile in terms of } \\
\text { HIVIAIDS knowledge }(\kappa)^{(1)} \\
\text { HIV }\end{array}$ & $11.4 \%$ & $11.6 \%$ & $10.03 \%$ & $10.0 \%$ \\
\hline Non-response to HIV-testing & $18.6 \%$ & $14.8 \%$ & $18.3 \%$ & $20.9 \%$ \\
\hline Response to HIV-testing & $81.4 \%$ & $85.2 \%$ & $81.7 \%$ & $79.1 \%$ \\
\hline Probability of HIV-positive (2) & $5.2 \%$ & $0.84 \%$ & $9.09 \%$ & $2.74 \%$ \\
\hline \multicolumn{5}{|c|}{$\begin{array}{l}\text { The total sample sizes for either the complete or the selected sample are based on males and females who are eligible for the randomized trial on HIV- } \\
\text { testing and at the same time have answered to the core DHS, i.e., we ignore all unit non-respondents because they do not provide any form of } \\
\text { information, either with respect to the core DHS or the actual HIV-testing, so that for them it is not possible to construct the IDIC entry. See Tables } 2 \text { and } \\
6 \text { for more detail. (1), (2) See Table } 5 \text { for further details }\end{array}$} \\
\hline
\end{tabular}

Table 7 shows that for either samples (based on tables 2 and 6) non-exposure to the information campaign $(I D I C=0)$ is - as intended - related to older cohorts in the population. Table 7 does not estimate causal paths, but it does nevertheless clarify the relation between the campaigns ( IDIC), the quantile distribution of $\kappa$ and HIV-status. Relative to older cohorts, younger ones ( IDIC $=1$ ) reveal a much lower HIV-prevalence: this is the case even when in fact younger cohorts have been exposed to the worst period of the epidemic. ${ }^{37}$ On the other hand Table 7 shows that any difference between IDIC groups with respect

${ }^{37}$ It is important to notice that whereas older cohorts have had more exposure to the epidemic (in terms of time), younger cohorts faced a more intensive exposure, i.e., the DHS-2003 interviews population members born in or after 1954 (i.e., ages 49 or younger in 2003). In November 1999 these individuals have been exposed to the AIDS epidemic since the start in the mid 1980s. But as shown in Figure 1 the epidemic took off - steeper gradient starting from the year 1990. Thus, exposure to the worst periods of the epidemic affects older cohorts when these 
to knowledge $\kappa$ is not statistically significant, i.e., when comparing $I D I C=0$ and $I D I C=1$, both are almost identical with respect to their sample percentage at the top $10^{\text {th }}$ percentiles of the knowledge $(\kappa)$ distribution. In sum, whereas Table 7 suggests that timing of the campaigns affect HIV-status, in 2003 the message from such campaigns have equipped all members in the population with regards to HIV/AIDS information ( $\kappa$-knowledge) irrespective of cohort status.

Table 8 provides the final third step estimates from the three part model in expression (3) using the complete sample (i.e., see Table 2), further complemented with Table B1 (Appendix B) with analogous estimates for the selected subgroup (i.e., see Table 6). In both cases - Table 8 and Table B1 - the first step consists on instrumenting $\kappa$-knowledge to obtain $\tilde{D}$ for each gender sub-sample. ${ }^{38}$ Once knowledge is instrumented we use Heckman's two step procedure combining a non-linear probability model for the selection equation (i.e. Probit estimation) and a linear probability model for the outcome to estimate the effects of both $\tilde{D}$ and IDIC on the HIV-status. ${ }^{39}$ The variable $\tilde{D}$ picks up the effect of acquired knowledge through information campaigns on HIV-status whereas IDIC picks up the effect of the timing of the information campaigns with specific reference to the most common route of transmission: sexual activity. Combining $\tilde{D}$ and IDIC implies picking up time effects of information campaigns on knowledge, on HIVstatus. Thus, even in the absence of panel data the use of external information (i.e., exogenous starting date of the information campaigns in Kenya) provides us with an important indicator ( $\tilde{D} \times I D I C)$ for the empirical evaluation of the introduction of information campaigns on the HIV-prevalence in Kenya. Table 8 assumes 6 different specifications: Model 1 to Model 3 ignore confounding effects whereas Model 4 to Model 6 allow for a set of covariates $X$ that control for all observed heterogeneity that may affect both the knowledge indicator and the outcome 'HIV-status', i.e., the set $X$ is carefully chosen to net out confounding effects that might otherwise be picked up by the important variables deemed as 'treatments' in

are already in their third decade of life and, therefore, more settled in life with regards to sexual behaviour (for good or for bad). Alternatively, the younger cohorts are exposed to the epidemic for shorter periods but the effects are more intensive, i.e., those aged 15 and younger in 1999 faced a prevalence rate of approximately $15 \%$ and this is approximately three times the prevalence rate prevailing during the early 1990s.

${ }^{38}$ The results for this first step estimation are the same as those in Table 4, Step1. 
our analysis (i.e., $\tilde{D}, I D I C$ and $\tilde{D} \times I D I C)$. Allowing for a careful selection of variables (see Table A3, Appendix A) we are confident that the coefficients associated with the policy variables of interest (i.e., $\tilde{D}$, $I D I C$ and $\tilde{D} \times I D I C$ ) are indeed clear from confounding effects.

${ }^{39}$ The full first step estimation (selection equation) uses 55 indicators for males and 82 indicators for females. Table 8 provides first step diagnostic estimates (e.g., LR-statistics) but do not expose the full set of estimated coefficients: these are available from the authors on demand. The same comments apply to Table B1 in Appendix B. 
Table 8: Effect of HIV/AIDS knowledge on HIV-status based on the complete sample (by gender)

\begin{tabular}{|c|c|c|c|c|c|c|}
\hline \multicolumn{7}{|c|}{ Males $(3,578)$} \\
\hline & Model 1 & Model 2 & Model 3 & Model 4 & $\begin{array}{c}\text { Model } 5 \\
(I C I D=0)\end{array}$ & $\begin{array}{c}\text { Model } 6 \\
(I C I D=1)\end{array}$ \\
\hline \multicolumn{7}{|l|}{ Selection Equation $(\delta$ ) } \\
\hline \multirow[b]{5}{*}{$\begin{array}{r}\text { strictions (df) } \\
\text { Pseudo R2 } \\
\end{array}$} & 3.578 & 3,578 & 3.578 & 3,568 & 2.972 & 596 \\
\hline & $\begin{array}{c}3,5 / 8 \\
22\end{array}$ & $\begin{array}{l}0,510 \\
22\end{array}$ & 22 & $\begin{array}{l}0,500 \\
22\end{array}$ & $\begin{array}{l}2,912 \\
22\end{array}$ & 16 \\
\hline & & n.a & n.a & 55 & 55 & 54 \\
\hline & $257.5(23)$ & $261(24)$ & $265(25)$ & $389(80)$ & $328(78)$ & $124(71)$ \\
\hline & 0.08 & 0.08 & 0.08 & 0.115 & 0.113 & 0.268 \\
\hline Instrumented Knowledge ( $\tilde{D})$ & $0.03^{\star \star}(0.009)$ & $0.033^{\star \star}(0.009)$ & $0.037^{\star *}(0.010)$ & $0.014(0.016)$ & $0.008(0.018)$ & $0.020(0.015)$ \\
\hline Sexual debut before $2000($ IDIC $=1$ ) & -- & $-0.048^{\star \star}(0.010)$ & $-0.047^{\star \star}(0.010)$ & $-0.013(0.016)$ & -- & -- \\
\hline Interaction variable: ( $\tilde{D} * I D I C$ ) & - & - & $-0.028(0.027)$ & $-0.030(0.028)$ & - & - \\
\hline Includes Covariates (1) & NO & NO & NO & YES & YES & YES \\
\hline \multicolumn{7}{|l|}{ Number of Observation: } \\
\hline Selection Equation & 3,578 & 3,578 & 3,578 & 3,568 & 2,972 & 596 \\
\hline Outcome Equation & 2,917 & 2,917 & 2,917 & 2,915 & 2,406 & 509 \\
\hline Lambda & $-0.022(0.026)$ & $-0.030(0.026)$ & $-0.03(0.026)$ & $-0.055 *(0.031)$ & $-0.060 *(0.038)$ & $-0.039 *(0.024)$ \\
\hline Rho $(\operatorname{corr}(W, Q))$ & -0.10 & -0.14 & -0.14 & -0.269 & $-0.27^{*}$ & -0.45 \\
\hline Wald $-\chi^{2}(d f)$ & $21.40(2)$ & $45.51(4)$ & $50.80(6)$ & $290.08(116)$ & $246.18(112)$ & $107.39(110)$ \\
\hline \multicolumn{7}{|c|}{ Females $(4,037)$} \\
\hline & Model 1 & Model 2 & Model 3 & Model 4 & $\begin{array}{c}\text { Model } 5 \\
(I C I D=0)\end{array}$ & $\begin{array}{c}\text { Model } 6 \\
(I C I D=1)\end{array}$ \\
\hline \multicolumn{7}{|l|}{ Selection Equation $(\delta)$} \\
\hline Number of observations & 4,037 & 4,037 & 4,037 & 4,037 & 3,406 & 631 \\
\hline Number of Exclusion restrictions & 63 & 63 & 63 & 64 & 62 & 44 \\
\hline Number of non-excluded variables & n.a & n.a & n.a & 30 & 30 & 30 \\
\hline in $X$ & $337(64)$ & $337(65)$ & $340(66)$ & $450(97)$ & $362(93)$ & $145(75)$ \\
\hline $\begin{array}{r}\text { LR for the Exclusion restrictions (df) } \\
\text { Pseudo R2 }\end{array}$ & 0.09 & 0.09 & 0.09 & 0.11 & 0.11 & 0.24 \\
\hline Instrumented Knowledge ( $\tilde{D}$ ) & $0.061^{\star *}(0.011)$ & $0.063 * *(0.010)$ & $0.066^{\star \star}(0.011)$ & $0.028 *(0.016)$ & $0.024(0.018)$ & $0.032(0.025)$ \\
\hline Sexual debut before $2000($ IDIC $=1)$ & -- & $-0.070^{\star \star}(0.013)$ & $-0.070 * \star(0.013)$ & $-0.058^{\star *}(0.018)$ & -- & -- \\
\hline Interaction variable: $(\tilde{D} * I D I C)$ & -- & -- & $-0.031(0.032)$ & $-0.019^{\star \star}(0.032)$ & -- & -- \\
\hline Includes Covariates (1) & NO & NO & NO & YES & YES & YES \\
\hline \multicolumn{7}{|l|}{ Number of Observation: } \\
\hline Selection Equation & 4,037 & 4,037 & 4,037 & 4,037 & 3,406 & 631 \\
\hline Outcome Equation & 3,269 & 3,269 & 3,269 & 3,269 & 2,756 & 513 \\
\hline Lambda & $-0.040(0.031)$ & $-0.048(0.031)$ & $-0.048^{\star}(0.030)$ & $-0.025(0.035)$ & $0.003(0.043)$ & $-0.04(0.037)$ \\
\hline Rho $(\operatorname{corr}(W, Q))$ & -0.142 & -0.17 & -0.17 & -0.094 & 0.011 & -0.25 \\
\hline Wald $-\chi^{2}(d f)$ & $53.59(2)$ & $81.88(4)$ & $85.69(6)$ & $325.11(66)$ & $266.88(62)$ & $110.93(62)$ \\
\hline \multicolumn{7}{|c|}{ 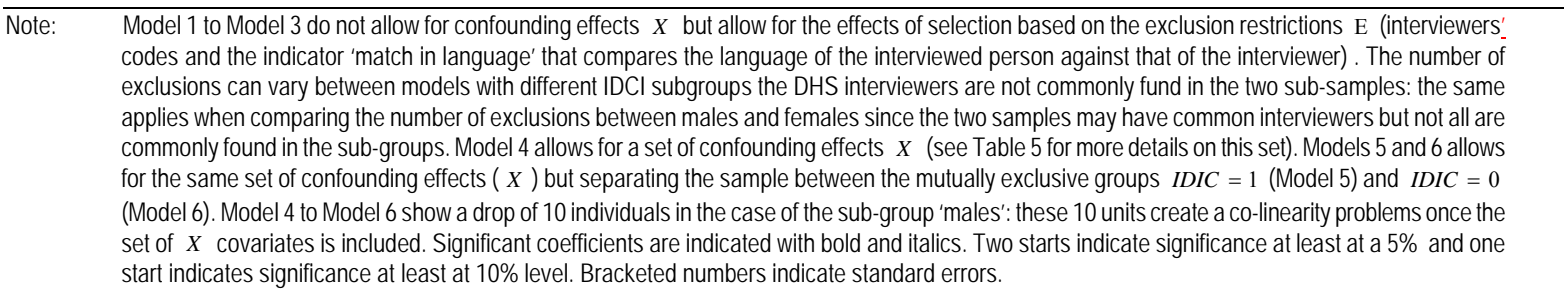 } \\
\hline
\end{tabular}

Ignoring confounding effects (Model 1) suggests that knowledge increases the chances of becoming

HIV-positive with a causal effect that is statistically significant for both males and females. Thus, based on 
the parsimonious specification in Model 1 we cannot find support for the positive effects that information campaigns ought to have with regards to reducing the prevalence rates through increasing knowledge and awareness. When 'timing of the information campaigns' is introduced (i.e., allow for IDIC in Model 2) the empirical evidence show that having stared sexual activity after the start of the information campaigns significantly reduces the chances of being HIV-positive even if (overall) more knowledge seems to be causal with respect to a HIV-positive status: the evidence suggests that awareness in the population has filtered through and individuals are knowledgeable but knowledge has arrived too late for those who where not aware of the epidemic before the start of their sexual life: again, the empirical evidence applies to both males and females. Model 3 further includes the interaction term between $\tilde{D}$ and IDIC. However, estimates from Model 3 show that whereas being more likely to start sexual life after having been treated by the intensive information campaigns (i.e., IDIC=1) statistically reduces the chances of becoming HIVpositive, the insignificance of the coefficients associated with the interaction term $\tilde{D}^{*}$ IDIC implies that individuals who are more likely to avoided risky behaviour as a result of the information campaigns are not necessarily more knowledgeable than those who being older are more likely to have started sexuality before the implementation of the intensive information campaigns. Again, these conclusions apply to both genders. Once we include confounding effects (Model 4) the estimates differ significantly between males and females. In the case of males, Model 4 shows that controlling for all possible confounding effects implies that $\tilde{D}$ and IDCI loose the initial significance with regards to the outcome HIV-status. Thus, any findings initially suggested by estimates from Model 1 to Model 3 were driven by an omitted variables problems; other covariates seem to have more power at explaining the outcome HIV-status than the actual policy related indicators. ${ }^{40}$ However, an important point to notice is the significant 'selection' effect, i.e., conditioning on the set of covariates $X$ and the set of exclusions $\mathrm{E}$ that jointly explain selection, the presence of unit nonresponse on HIV-testing may be inducing a bias on the coefficients associated with the

\footnotetext{
${ }^{40}$ In particular, it seems that for males being older, higher education, living in a rural area, declaring to feel embarrassed when buying condoms and declaring to know about the benefits of family planning are all statistically significant at explaining an HIV-positive status while a higher households size and correct attitudes towards women are all statistically associated with a lower chance of being HIV-positive.
} 
policy related variables, and it is for this reason that estimates from Model 4 (males) ought to be analysed with caution. The results for females are very different: in their case Model 4 suggests that even after controlling for all possible observed confounding effects $(X)$ the policy variables remain statistically significant, i.e., the coefficients associated with both $\tilde{D}$ and IDIC remain statistically significant and display exactly the same causal effect with regards to the outcome HIV-status. These evidence suggest that when females arrive on time to benefit from the campaigns (i.e., IDIC =1) they helped the females in the population to avoid a positive HIV-status, with results that are statistically significant. Moreover, it seems that in the case of females there is no effect from selection, i.e., controlling for all covariates in $X$, and given $\mathrm{E}$, females who declined to be tested for HIV are not statistically different from those who accepted to take the test. The last two models (i.e., Model 5 and Model 6) separate the two gender samples according to the binary outcome IDIC with the intention to isolate the effect of knowledge according to the sub-group with different time exposure to the information campaigns. Both Model 5 and Model 6 are based on specifications that allow for confounding effects $(X)$. The empirical evidence from these models suggests that the coefficients for the variable $\tilde{D}$ are not statistically causal for the outcome HIV-status, i.e., separating samples according to timing and exposure to the information campaigns (IDIC) implies that the variable knowledge (i.e., $\tilde{D}$ ) becomes too homogenous within each of the samples and cannot discriminate to become statistically significant at explaining the outcome HIV-status. These comments apply equally to males and females in the population. However, as was the case with estimates from Model 4, estimates from Model 5 and Model 6 show that in the case of males the effects of selection are significant and negative, i.e., non-respondents to HIV-testing may cause a bias on the coefficients associated with the variable $\tilde{D}$ such that the true unbiased coefficient is lower in magnitude and may even be significant at explaining HIVstatus.

Finally, it remains to be said that very similar comments apply when similar estimates to those in Table 8 are based on the selected sample (i.e., according to the sample as described in Table 6). These estimates are shown in Table B1, Appendix B. We may interpret the similarity in results between Table 8 and Table B1 to indicate that reverse causality, if present at all, would be equally found in either the 
complete or the selected sample since both sets of estimates lead to identical policy advice with regards to the benefits from the use of information campaigns. Since eliminating individuals who declare to have been tested may indeed inflict some crude selection bias on our behalf, we choose to back our empirical work and intended conclusion on the evidence obtained from the complete sample, that is, using Table 8.

\section{Conclusions}

This paper examines the effect of HIV/AIDS related knowledge on HIV-status. At the date of print an effective medical treatment for the eradication of the HIV virus is not yet known. However, to a large extent HIV/AIDS is a behavioural condition in that it may be avoidable if individuals take the necessary precaution, i.e., informing individuals about the illness, its consequences and the increasing awareness about how to reduce the risk of infection all remain cornerstone policies to reduce HIV-prevalence to some minimum levels. This is especially true in Sub-Saharan economies where the HIV-prevalence remains relatively high and where existing antiretroviral treatments continue to be too expensive for the vast majority of individuals in these populations. The question is to what extent are information campaigns effective at modifying individual's behaviour and furthermore, to what extent declared modified behaviour translates into prudent behaviour thus effectively reducing the chances of becoming HIV-positive. Using the Kenya Demographic and Health Survey from 2003 (DHS-2003) we estimate the effect of HIV/AIDS related knowledge on both declared 'attitudes' (that may be thought as being directly targeted by information campaigns) and HIV-status. The DHS-2003 is a cross-section survey representative of the Kenyan population with regards to social, demographic and economic indicators. Furthermore, the DHS2003 collects blood samples from a representative sample of males and females thus providing random sample data on the HIV-status of the Kenyan population in 2003. The problem in using a cross-section survey is that of possible endogeneity effects: for example, not being able to identify third variables that determine causal effects between knowledge and HIV-status, but also not being able to identify the path in the causal relation between HIV/AIDS-knowledge and HIV-status (i.e., reverse causality problems). We use instruments to control for potential endogeneity while experimenting with different sub-samples from the data that could differ with respect to reverse causality. Furthermore, we estimate the conditional causal path 
from knowledge to HIV-status accounting for the possibility of selection bias that may arise because not all of those randomly selected to give blood accept to do so. Our estimates suggest that knowledge from information campaigns filters through in the population. However, it is only in the case of younger females that we find a lower HIV-prevalence associated with better knowledge and intended behaviour, i.e., the HIV-prevalence is statistically lower for younger females that received the benefits from the information campaigns before the expected age of starting their sexual life. In the case of males neither knowledge nor timing of the information campaigns can explain their HIV-status. However, a non-negligent percentage of individuals randomly selected for HIV-testing declines in fact to take part in the test and our estimates suggest that refusals to be tested are inducing a bias on the policy parameters in question. What is more important, however, is that conditional on a set of covariates that also explain HIV-status, the selected nonrespondents are more likely to be HIV-positive. It is therefore important to be cautious when using data sets such as the DHS if one wants to understand the actual HIV-prevalence in the population but ignores HIVtesting nonresponse.

\section{References}

Becker, G.S, M. Grossman and K.M. Murphy, (1994), “An empirical analysis of cigarette addiction”, American Economic Review, 84, 3, 396-218

De Walque, D. (2007), "How does the impact of an HIV/AIDS information campaign vary with educational attainment? Evidence from rural Uganda", Journal of Development Economics, 84, 686-714

Demographic and Health Surveys, Measured DHS Organization, USAID, www.measuredhs.org

Frölich, M. (2007): "Nonparametric IV estimation of local average treatment effects with covariates", Journal of Econometrics, 139, 35-75.

Grossman, M. (1972), “On the concept of health capital and the demand for health”, Journal of Political Economy, 80, $2,223-255$

Grossman, M. (1999), “The Human Capital model of the demand for health”, NBER Working Papers 7078, Cambridge, MA

Haile, P. and E. Tamer, (2003), "Inference with an incomplete model of English auctions", Journal of Political Economy, 111, 1-51

Juster, T. and J. Smith (1997), "Improving the quality of economic data: Lessons from the HRS and AHEAD”, Journal of the American Statistical Association, 92, 1268-1278 
Kamali, A., M. Qugley, J. Nakiyigu, J.K Kinsman, J. Kengaya-Kayondo, P. Gopal, A. Ojwiya, A. Hagues, P. Carpenter and L.M. Witworth, (2003), "Sindromic management of sexually transmitted infections and behaviour change interventions on transmission of HIV-1 in rural Uganda: a community randomized trial", The Lancet, 361, 645-652.

Levy, A. (2002), “A lifetime portfolio of risky and risk-free sexual behaviour and prevalence of AIDS”, The Journal of Health Economics, 21, 993-1007

Lopez, A., C.D. Mathers, M. Ezzati, D.T. Jamison and C.J.L. Murray, (2006), "Global Burden of Disease and risk factors", Wold Bank Publications, The World Bank, Washington

Magnac, T. and E. Maurin, (2007), "Identification and Information on monotone binary models", Journal of Econometrics, 127, 76-104

Manski, C., (1989), “Anatomy of the selection problem”, Journal of Human Resources, 24, 343-360

Manski, C., (1990), "Non-parametric bounds on treatment effects", American Economic Review, Papers \& Proceedings, 80, 319-323

Montaner, J., R. Hogg, E Wood, T Kerr, M Tyndall, AR Levy, R. Harrigan, “The case for expanding access to highly active antiretroviral therapy to curve the growth of the HIV epidemic", 2006, The Lancet, 368: 531-536.

Partchev, I. (2004), “A visual guide to Item Response Theory”, Friedrich Schiller Universität Jena, Germany

UNAIDS, (2006), “AIDS Epidemic Updates: report on HIV/AIDS, 2006”, UNAIDS/06.29E ISBN 9291735426, Geneva

WHO, (2005), "HIV/AIDS epidemiological surveillance report for the WHO African region - 2005 update", WHO Publications, Harare WHO Regional Office for Africa and WHO-Geneva, Geneva

Yamba, C.B. (1997), "Cosmologies in Turmoil: Witch-finding and AIDS in Chiawa, Zambia”, Journal of the International African Institute, 67, 200-223

Zulu, E.M. (2002), “Sexual risk-taking in the slums of Nairobi, Kenya (1993-1998)”, Population Studies, 56, 311-323 


\section{Appendix A}

Table A1: Knowledge about HIV/AIDS (Number of individuals answering yes, no, don't know)

\begin{tabular}{|c|c|c|c|c|c|c|c|c|c|c|}
\hline & \multicolumn{5}{|c|}{ Men (3,578 observations) } & \multicolumn{5}{|c|}{ Women (8,187 observations) } \\
\hline & Yes & No & $\begin{array}{l}\text { Don't } \\
\text { know }\end{array}$ & $\begin{array}{c}\text { missi } \\
\mathrm{ng}\end{array}$ & $\mathrm{n} / \mathrm{a}$ & Yes & No & $\begin{array}{l}\text { Don't } \\
\text { know }\end{array}$ & $\begin{array}{c}\text { missi } \\
\mathrm{ng}\end{array}$ & n/a \\
\hline Have you ever heard of an illness called AIDS? & 3541 & 35 & & 2 & & 8052 & 129 & & 6 & \\
\hline Is there anything a person can do to avoid getting AIDS/HIV? & 3259 & 154 & 128 & & 37 & 6912 & 388 & 751 & 1 & 135 \\
\hline \multicolumn{11}{|l|}{ What can a person do? (Asks for spontaneous answers) ${ }^{1}$} \\
\hline a) Abstain from sex & 1927 & & & & 319 & 3475 & & & 2 & 1275 \\
\hline b) Use condoms & 1993 & & & & 319 & 3284 & & & 2 & 1275 \\
\hline c) Stay faithful to one partner & 2085 & & & & 319 & 4477 & & & 2 & 1275 \\
\hline d) Limit number of sex partners & 412 & & & & 319 & 414 & & & 2 & 1275 \\
\hline e) Avoid prostitutes & 335 & & & & 319 & 346 & & & 2 & 1275 \\
\hline f) Avoid promiscuous partners & 189 & & & & 319 & 222 & & & 2 & 1275 \\
\hline g) Avoid sex with homosexuals & 9 & & & & 319 & 10 & & & 2 & 1275 \\
\hline h) Avoid sex with drug users & 41 & & & & 319 & 29 & & & 2 & 1275 \\
\hline i) Avoid blood transfusion & 244 & & & & 319 & 448 & & & 2 & 1275 \\
\hline j) Avoid injections & 172 & & & & 319 & 463 & & & 2 & 1275 \\
\hline k) Avoid sharing razors/blades & 459 & & & & 319 & 851 & & & 2 & 1275 \\
\hline I) Avoid kissing & 9 & & & & 319 & 38 & & & 2 & 1275 \\
\hline m) Avoid mosquito bites & 3 & & & & 319 & 13 & & & 2 & 1275 \\
\hline n) Seek protection from traditional healer & 4 & & & & 319 & 4 & & & 2 & 1275 \\
\hline z) No spontaneous answers given & 6 & & & & 319 & 27 & & & 2 & 1275 \\
\hline $\begin{array}{l}\text { Can people reduce their chances of getting HIV by having just one } \\
\text { sex partner who has no other partners? }\end{array}$ & 3115 & 111 & 33 & & 319 & 6462 & 355 & 93 & 2 & 1275 \\
\hline Can a person get HIV from mosquito or insect bites? & 415 & 2620 & 224 & & 319 & 1151 & 5003 & 756 & 2 & 1275 \\
\hline $\begin{array}{l}\text { Can people reduce their chances of getting the AIDS virus by using a } \\
\text { condom every time they have sex? }\end{array}$ & 2510 & 493 & 255 & 1 & 319 & 4899 & 1311 & 695 & 7 & 1275 \\
\hline $\begin{array}{l}\text { Can a person get the AIDS virus by sharing food utensils with a } \\
\text { person who has AIDS? }\end{array}$ & 289 & 2838 & 129 & 3 & 319 & 765 & 5750 & 383 & 14 & 1275 \\
\hline $\begin{array}{l}\text { Can people reduce their chances of getting the AIDS virus by not } \\
\text { having sex at all? }\end{array}$ & 3124 & 121 & 11 & 3 & 319 & 6375 & 464 & 63 & 10 & 1275 \\
\hline Is it possible for a healthy-looking person to have the AIDS virus? & 3178 & 236 & 124 & 3 & 37 & 6854 & 719 & 467 & 12 & 135 \\
\hline $\begin{array}{l}\text { Can the virus that causes AIDS be transmitted from a mother to a } \\
\text { child? }\end{array}$ & 3122 & 176 & 243 & & 37 & 7044 & 335 & 671 & 2 & 135 \\
\hline during pregnancy? & 2622 & 384 & 115 & 1 & 456 & 5673 & 947 & 420 & 4 & 1143 \\
\hline during delivery? & 2451 & 441 & 229 & 1 & 456 & 5429 & 827 & 787 & 1 & 1143 \\
\hline during breastfeeding? & 2388 & 443 & 291 & & 456 & 5826 & 618 & 599 & 1 & 1143 \\
\hline $\begin{array}{l}\text { Can a mother who is infected with the AIDS virus reduce the risk of } \\
\text { giving the virus to the baby by taking certain drugs during } \\
\text { pregnancy? }\end{array}$ & 1322 & 771 & 1018 & 11 & 456 & 2665 & 1992 & 2385 & 2 & 1143 \\
\hline Have you ever heard of VCT? & 2239 & 1300 & & 2 & 37 & 4042 & 4004 & & 6 & 135 \\
\hline Do you agree with this statement? Condoms contain HIV & 284 & 2230 & 1057 & 7 & & $\mathrm{n} / \mathrm{a}$ & n/a- & $\mathrm{n} / \mathrm{a}$ & $\mathrm{n} / \mathrm{a}$ & $\mathrm{n} / \mathrm{a}$ \\
\hline
\end{tabular}

Note: n/a means not applicable, i.e. question was skipped due to routing of the questionnaire.

1) This question asked for spontaneous answers without giving any list of examples. The numbers given for Yes represent the number of people spontaneously mentioning this item. 
Table A2: HIV-risk related attitudes

\begin{tabular}{|c|c|c|c|}
\hline & Mnemonic & $\begin{array}{c}\text { Men } \\
\text { (3,578 observations) }\end{array}$ & $\begin{array}{c}\text { Women } \\
\text { (8,187 observations) }\end{array}$ \\
\hline $\begin{array}{l}\text { Average number of partners with whom had sexual intercourse during } \\
\text { last calendar year (including wife(ves) ) }\end{array}$ & $\begin{array}{l}\text { NUMSXP } \\
\text { \% with zero Partners } \\
1 \text { or more partners }\end{array}$ & $\begin{array}{l}0.28(0.008) \\
1.25(0.92)\end{array}$ & $\begin{array}{c}0.30(0.005) \\
1.03(0.12)\end{array}$ \\
\hline $\begin{array}{l}\text { Dummy }=1 \text { if individual's common method of contraception is the use of } \\
\text { condom 1) }\end{array}$ & USECON & $0.14(0.006)$ & $0.27(0.005)$ \\
\hline $\begin{array}{l}\text { Dummy }=1 \text { if individual agrees that it is acceptable to advertise condoms } \\
\text { in the radio }\end{array}$ & OKCONR & $0.76(0.007)$ & $0.69(0.005)$ \\
\hline $\begin{array}{l}\text { Dummy }=1 \text { if individual agrees that it is acceptable to advertise condoms } \\
\text { in the television }\end{array}$ & OKCONT & $0.73(0.007)$ & $0.66(0.005)$ \\
\hline $\begin{array}{l}\text { Dummy }=1 \text { if individual agrees that it is acceptable to advertise condoms } \\
\text { in newspapers and magazines }\end{array}$ & OKCONW & $0.77(0.007)$ & $0.67(0.005)$ \\
\hline $\begin{array}{l}\text { Dummy }=1 \text { if individual agrees that it is acceptable to teach children } \\
\text { about condoms }\end{array}$ & YCONDK & $0.61(0.008)$ & $0.59(0.005)$ \\
\hline $\begin{array}{l}\text { Dummy }=1 \text { if individual declared to have discussed how to avoid } \\
\text { HIVIAIDS with partner'1) }\end{array}$ & TAKP & $0.82(0.009)$ & $0.64(0.005)$ \\
\hline \multicolumn{4}{|l|}{ (Exclusive to Males) } \\
\hline $\begin{array}{l}\text { Dummy }=1 \text { if the male declares to agree with the statement 'women have } \\
\text { the right to ask man to put a condom' }\end{array}$ & ATTWC1 & $0.66(0.008)$ & $n / a$ \\
\hline $\begin{array}{l}\text { Dummy }=1 \text { if the male declares to agree with the statement } \\
\text { 'contraception is not just women's business' }\end{array}$ & ATTWC2 & $0.71(0.008)$ & n/a \\
\hline $\begin{array}{l}\text { Dummy }=1 \text { if the responding male declares no in the statement 'it is } \\
\text { embarrassing to buy condoms' }\end{array}$ & EMBRS & $0.60(0.008)$ & $n / a$ \\
\hline $\begin{array}{l}\text { Dummy }=1 \text { if the responding male disagrees with the statement 'condoms } \\
\text { can be reused if you wash it after use' }\end{array}$ & KNOWRC & $0.78(0.007)$ & $n / a$ \\
\hline \multicolumn{4}{|c|}{$\begin{array}{l}\text { Note: } \\
\text { All variables are defined in positive terms. For example, the variable KNOWRC was originally asked as 'I will now read you a statement and you will tell } \\
\text { me if you agree or disagree: it is ok to re-use condoms if you wash it'. Thus, we define the variable KNOWRC=1 if the answer to the agreement } \\
\text { question is 'no'. The same applies to all variables in this table. (1) Answer to this question is based on reduced samples. In the case of 'common } \\
\text { contraceptive method' we exclude individuals who declare not to have yet sexually debuted ( } 571 \text { males and 1,397 females). For 'talked about avoiding } \\
\text { AIDS with current partner' we exclude individuals with no current partner (1,739 males and 3,403 females). Bracketed numbers show standard errors. }\end{array}$} \\
\hline
\end{tabular}

Table A3: Distribution of selected demographic, social and economic characteristics

\begin{tabular}{|c|c|c|c|c|}
\hline $\begin{array}{l}\text { Socio-Economic covariates } \\
\text { common to both genders }\end{array}$ & $\begin{array}{l}\text { Socio-Economic variables } \\
\text { exclusive to MALES }\end{array}$ & $\begin{array}{l}\text { Variables relating to Health } \\
\text { knowledge }\end{array}$ & $\begin{array}{l}\text { Variables relating to } \\
\text { Household and wealth } \\
\text { information }\end{array}$ & $\begin{array}{c}\text { Common Instrumental } \\
\text { Variables }\end{array}$ \\
\hline \multirow{5}{*}{$\begin{array}{c}\text {-Age } \\
\text {-Origin: city, town, rural, } \\
\text { abroad } \\
\text {-Immigrant } \\
\text {-Education level } \\
\text {-Literacy test } \\
\text {-Religion } \\
\text {-Household positions } \\
\text {-Smoker } \\
\text {-Alcohol drinking } \\
\text {-Partner present } \\
\text {-Ideal number of children } \\
\text { (kids, girls, boys) } \\
\text {-Employment status } \\
\text { - Industrial sector } \\
\text { - language of interview } \\
\text {-Schooling status } \\
\text {-Who has say on household } \\
\text { decisions (e.g., buying, } \\
\text { expenditure, visits, etc.) } \\
\text { - Age first becoming parent }\end{array}$} & $\begin{array}{c}\text { - Time spent away from home } \\
\text { - Some views on } \\
\text { husband/partner's views of } \\
\text { wives and rights } \\
\text { - Good Body Mass Index for } \\
\text { female and for last born }\end{array}$ & \multirow{5}{*}{$\begin{array}{c}\text { - Knows about contraceptives } \\
\text { - Knows traditional method } \\
\text { - Knows about family planning } \\
\text { - Knows about STD } \\
\text { - Knows about malaria } \\
\text { - Indicators for children's } \\
\text { health but only on last born } \\
\text { (females) } \\
\text { - Knows about } \\
\text { diarrhoea/children/ treatment }\end{array}$} & \multirow{5}{*}{$\begin{array}{c}\text { - Location (city, rural, capital) } \\
\text { - wealth index } \\
\text { - Durables (e.g., car, } \\
\text { electricity, television, radio, } \\
\text {...) } \\
\text { - Water conditions } \\
\text { - Toilet conditions } \\
\text { - State of households as seen } \\
\text { from interviewer } \\
\text { - Ownership of household } \\
\text { and land } \\
\text { - Household size } \\
\text { - Number of kids below age } 5 \\
\text { - Number of families } \\
\text { - Percentage covered by } \\
\text { mosquito nets } \\
\text { - Percentage distribution of } \\
\text { sleeping rooms }\end{array}$} & $\begin{array}{l}\text { Non-self regional cluster } \\
\text { mean value of : } \\
\text { - Frequency of radio use } \\
\text { - Frequency of TV use } \\
\text { - Frequency of News Paper } \\
\text { use }\end{array}$ \\
\hline & $\begin{array}{c}\text { Socio-Economic variables } \\
\text { exclusive to FEMALES }\end{array}$ & & & $\begin{array}{c}\text { Instrumental Variables } \\
\text { exclusively found in MALES } \\
\text { questionnaire }\end{array}$ \\
\hline & $\begin{array}{l}\text {-Knowledge about fertility } \\
\text { (e.g., ovulation, child's illness, } \\
\text { wife's pregnancy status) } \\
\text { - Child's information/ } \\
\text { investment (last born) } \\
\text { - Views on partner's rights } \\
\text { (e.g., right to beating wife if } \\
\text { she burns food) } \\
\text { - Current preanancy status }\end{array}$ & & & $\begin{array}{c}\text { Non-self regional cluster } \\
\text { mean value of: } \\
\text { - Having heard about Family } \\
\text { Planning on Radio } \\
\text { - Having heard about Family } \\
\text { Planning on TV } \\
\text { - Having heard about Family } \\
\text { Planning from Newspapers }\end{array}$ \\
\hline & $\begin{array}{l}\text { - Number of births last } 4 \text { yeas } \\
\text { - Body Mass Index for female } \\
\text { and for last born }\end{array}$ & & & $\begin{array}{l}\text { Instrumental Variables } \\
\text { exclusively found in } \\
\text { FEMALES questionnaire }\end{array}$ \\
\hline & & & & $\begin{array}{c}\text { Non-self regional cluster } \\
\text { mean values of: } \\
\text { - Having heard about } \\
\text { condoms on Radio } \\
\text { - Having heard about } \\
\text { condoms on TV } \\
\text { - Having heard about } \\
\text { condoms from Newspapers }\end{array}$ \\
\hline
\end{tabular}




\section{Appendix B}

Table B1: Effect of HIV/AIDS knowledge on HIV-status: Selected sample of individuals who have never had an HIVtest previous to the date of the implementation of the DHS survey (by gender)

\begin{tabular}{|c|c|c|c|c|c|c|}
\hline \multicolumn{7}{|c|}{ Males $(2,954)$} \\
\hline & Model 1 & Model 2 & Model 3 & Model 4 & $\begin{array}{c}\text { Model } 5 \\
(I C I D=0)\end{array}$ & $\begin{array}{l}\text { Model } 6 \\
(\text { ICID = 1) }\end{array}$ \\
\hline \multicolumn{7}{|l|}{ Selection Equation ( $\delta$ ) } \\
\hline Number of observations & 2,954 & 2,954 & 2,954 & 2,945 & 2,387 & 558 \\
\hline Number of Exclusion restrictions & $\begin{array}{l}2,904 \\
22\end{array}$ & 22 & 22 & 22 & 22 & 16 \\
\hline Number of non-excluded variables & n.a & n.a & n.a & 55 & 55 & 54 \\
\hline in $X$ & $217(23)$ & $220(24)$ & $223(25)$ & $343(80)$ & $289(78)$ & $119(71)$ \\
\hline $\begin{array}{r}\text { LR for the Exclusion restrictions (df) } \\
\text { Pseudo R2 }\end{array}$ & 0.08 & 0.08 & 0.08 & 0.12 & 0.13 & 0.26 \\
\hline Instrumented Knowledge ( $\tilde{D})$ & $0.03^{* *}(0.010)$ & $0.034^{\star \star}(0.010)$ & $0.037^{\star \star}(0.011)$ & $0.014(0.017)$ & $0.009(0.019)$ & $0.020(0.017)$ \\
\hline Sexual debut before $2000($ IDIC $=1)$ & -- & $-0.046^{\star \star}(0.010)$ & $-0.045^{\star \star}(0.010)$ & $-0.013(0.016)$ & -- & -- \\
\hline Interaction variable: $(\tilde{D} * I D I C)$ & -- & -- & $-0.026(0.029)$ & $-0.025(0.030)$ & -- & -- \\
\hline Includes Covariates ${ }^{(1)}$ & NO & NO & NO & YES & YES & YES \\
\hline \multicolumn{7}{|l|}{ Number of Observation: } \\
\hline Selection Equation & 2,954 & 2,954 & 2,954 & 2,945 & 2,387 & 558 \\
\hline Outcome Equation & 2,425 & 2,425 & 2,425 & 2,423 & 1,947 & 476 \\
\hline Lambda & $-0.014(0.27)$ & $-0.020(0.027)$ & $-0.02(0.028)$ & $-0.054 *(0.032)$ & $-0.050(0.039)$ & $-0.045^{*}(0.025)$ \\
\hline Rho $(\operatorname{corr}(W, Q))$ & -0.07 & -0.10 & -0.094 & -0.268 & -0.23 & -0.50 \\
\hline Wald $-\chi^{2}(d f)$ & $15.25(2)$ & $36.53(4)$ & $40.47(6)$ & $266.91(116)$ & $230.71(112)$ & $105.75(110)$ \\
\hline \multicolumn{7}{|c|}{ Females $(3,349)$} \\
\hline & Model 1 & Model 2 & Model 3 & Model 4 & $\begin{array}{l}\text { Model } 5 \\
(\text { ICID }=0)\end{array}$ & $\begin{array}{c}\text { Model } 6 \\
(I C I D=1)\end{array}$ \\
\hline \multicolumn{7}{|l|}{ Selection Equation $(\delta)$} \\
\hline Number of observations & 3,349 & 3,349 & 3,349 & 3,349 & 2.761 & 588 \\
\hline Number of Exclusion restrictions & 63 & 63 & 63 & 63 & 62 & 41 \\
\hline Number of non-excluded variables & n.a & n.a & n.a & 30 & 30 & 29 \\
\hline in $X$ & $300(64)$ & $300(65)$ & $302(66)$ & $380(96)$ & $290(93)$ & $128(71)$ \\
\hline $\begin{array}{r}\text { LR for the Exclusion restrictions (df) } \\
\text { Pseudo R2 }\end{array}$ & 0.094 & 0.094 & 0.094 & 0.12 & 0.11 & 0.22 \\
\hline Instrumented Knowledge $(\tilde{D})$ & $0.060^{\star \star}(0.011)$ & $0.063 * *(0.011)$ & $0.067^{\star \star}(0.012)$ & $0.033^{* \star}(0.017)$ & $0.027(0.019)$ & $0.041(0.028)$ \\
\hline Sexual debut before $2000($ IDIC $=1)$ & -- & $-0.067^{\star *}(0.014)$ & $-0.067^{\star \star}(0.014)$ & $-0.053^{\star \star}(0.018)$ & -- & -- \\
\hline Interaction variable: ( $\tilde{D} * I D I C)$ & -- & - & $-0.029(0.033)$ & $-0.015(0.033)$ & -- & -- \\
\hline Includes Covariates (1) & NO & NO & NO & YES & YES & YES \\
\hline \multicolumn{7}{|l|}{ Number of Observation: } \\
\hline Selection Equation & 3,349 & 3,349 & 3,349 & 3,349 & 2,761 & 588 \\
\hline Outcome Equation & 2,733 & 2,733 & 2,733 & 2,733 & 2,256 & 477 \\
\hline Lambda & $-0.034(0.032)$ & $-0.041(0.032)$ & $-0.041(0.032)$ & $-0.021(0.037)$ & $-0.002(0.046)$ & $-0.04(0.041)$ \\
\hline Rho $(\operatorname{corr}(W, Q))$ & -0.124 & -0.152 & -0.151 & -0.080 & -0.008 & -0.24 \\
\hline Wald $-\chi^{2}(d f)$ & $45.27(2)$ & $70.36(4)$ & $72.61(6)$ & $284.23(66)$ & $235.38(62)$ & $95.10(60)$ \\
\hline
\end{tabular}




\section{Appendix C: AIDS/HIV knowledge measurement}

Central to the empirical analysis in this paper is the measurement of AIDS/HIV knowledge on an individual level. Knowledge may come about in very different facets, including knowledge about possibilities to reduce the risk of becoming infected, knowledge of treatment possibilities or detailed medical knowledge on certain aspects of the virus. In addition, lack of knowledge may also materialize in two ways: either not knowing or having false knowledge, e.g. believing that mosquitoes can transfer HIV. The DHS questionnaires contain a number of very detailed questions to elicit knowledge and awareness of AIDS/HIV, which we analyze in more detail in this appendix. It turns out that, for those questions asked in the DHS surveys, a one factor interpretation of knowledge works very well. I.e. knowledge can be measured on a one-dimensional scale such that individuals who are likely to respond correctly to some of the questions are also likely to respond correctly to the other questions. There does not seem to be a clear second dimension of knowledge which would permit us to enhance our analysis. ${ }^{41}$

We are going to measure knowledge in three different ways. The simplest is the number of correct answers on knowledge questions. This crude measure has the disadvantage that it does not identify whether knowledge can be considered as one-dimensional or whether the questions measure very different aspects of knowledge. In addition, it does not weight the questions according to their difficulty. The second measurement relies on a principal components analysis of the knowledge questions. It turns out that the inter-term consistency is very high and that the first principal component captures most of the variance with very similar factor loadings. This indicates that the knowledge questions are most appropriately to be considered as measuring a single latent knowledge variable. The third and most refined measurement relies on item response theory (IRT) which permits the latent knowledge factor to affect the answering patterns in more complex ways. To permit a flexible specification we use a 3 parameter logistic model, which distinguishes between difficulty, discrimination and random guessing. Overall, these three different measures turn out to be quite highly correlated.

\footnotetext{
${ }^{41}$ A possible interpretation of this finding could be that information campaigns may have been effective in conveying a clear and unambiguous message of the problem. But this is only a tentative conjecture.
} 
Table A.1 shows the list of questions of the DHS survey which explicitly elicit information about AIDS/HIV knowledge. All but the last two questions represent a coherent block of the survey on AIDS. The last question was part of the survey module "Marriage". Table A.1 also shows the responses to these questions, where the column 'not applicable' shows the number of individuals who have not been asked this question. Individuals who did not answer affirmatively the first question were not asked the follow up questions, except for the last one. Similarly individuals who did not affirm to the second question were asked only some of the follow up questions. For these individuals we assume in the following that they have no knowledge for the questions that were skipped. Most of the questions could be answered with 'yes', 'no', or 'don't know'. An answer is considered as correct if the answer is 'yes', except for those questions marked in italics in Table A.1 where the correct answer would be 'no'. On the other hand, the question "What can a person do?" asked for spontaneous answers, with the interviewer prompting "Anything else" to elicit further replies. These answers are thus not anchored at all. Most people mentioned between 4 and 6 of the items named (a) to (n) in Table A.1 and only very few mentioned more than 8 . Since several of the items (a) to (n) are similar in meaning, their mentioning is sometimes negatively correlated. For most of the later analysis we thus grouped the items into four categories: Abstain/faithful $(=a, c, d)$, condoms $(=b)$, avoid risk groups $(=e, f, g, h)$, avoid non-sterilized needles/razors $(=\mathrm{i}, \mathrm{j}, \mathrm{k})$. The items $1, m$ and $n$ are ignored as they were rarely mentione and since there was a closed-form question on mosquitoes shortly after. For each of these four categories each person either mentioned at least one of these items or none.

To analyze these answers and to examine whether they could be well considered as reflecting a single knowledge variable or whether multiple dimensions would be more appropriate, several principal component analyses were conducted. The answers were coded dichotomously as correct or not and the PCA was performed on the basis of the tetrachoric correlations, which are usually used for binary variables. If the first principal component captures most of the variance and the further principal components are much smaller, of similar size and more diffuse, one could consider reasonably well the answers to the above questions being generated by one latent factor of knowledge. A further tool to examine the appropriateness of the one-factor interpretation is given by Cronbach's $\alpha$. Cronbach's $\alpha$ was developed in the psychometric literature to measure the reliability of a psychometric instrument, in particular to assess whether a set of 
items can be considered to measure a single latent variable. It is also frequently used in designing questionnaires and tests in the education and social sciences. Alternative measures have been suggested but Cronbach's $\alpha$ seems to be most widely used to measure inter-item consistency. It can take at most the value 1 and values above 0.7 are often considered as indicating that a one-factor representation is reasonable. To select the most appropriate way of measuring knowledge, several PCA with increasing sets of regressors were conducted, separately for men and women. More details are available in an appendix available from the authors upon request.

Given that the PCA analysis did not provide evidence against a single latent factor of the answer patterns to the HIV knowledge questions, the first principal component could be considered as a measure of latent knowledge. More refined methods developed in psychometrics are known as item response theory (IRT). IRT contains statistical models that specify the probability to give a correct answer as a function of a latent ability or knowledge variable. Let $\kappa_{i}$ be the latent HIV knowledge of person $i$ and consider the answer to a (dichotomous) question $j$. The probability of answering correctly is specified as

$$
\operatorname{Pr}(\text { answer to question j correct } \mid \kappa)=c_{j}+\frac{1-c_{j}}{1+e^{-a_{j}\left(\kappa-b_{j}\right)}}
$$

The values $a_{j}, b_{j}$ and $c_{j}$ are unknown question-specific parameters. The parameter $b_{j}$ captures the difficulty of a question; $a_{j}$ represents the discrimination of the item. As an example, if $b_{j}$ is zero, a large value of $a_{j}$ means that someone with a $\kappa_{i}$ to the right of zero answers correctly with a relatively large probability. Someone with $\kappa_{i}$ a little bit to the left of zero answers correctly with low probability. On the other hand, if $a_{j}$ is small, the chances of a correct answer are about the same for these two persons. Finally, the parameter $c_{j}$ captures random guessing, i.e. the probability that someone with zero knowledge may answer correctly by chance in a multiple choice question. For more details on IRT see Partchev (2004). 